Attainment grouping in English secondary schools: A national survey of current practices

Becky Taylor ${ }^{\text {a* }, ~ J e r e m y ~ H o d g e n ~}{ }^{\mathrm{a}}$, Antonina Tereshchenko ${ }^{\mathrm{a}}$ and Gabriel

Gutiérrez

${ }^{a}$ Department of Curriculum Pedagogy and Assessment, UCL Institute of Education, London, UK; ${ }^{b}$ Department of Social Policy, London School of Economics, London, UK.

* becky.taylor@ucl.ac.uk 


\title{
Attainment grouping in English secondary schools: A national survey of current practices
}

\author{
Attainment grouping is a prevalent yet controversial practice, used in most English \\ schools and on the rise internationally, despite evidence that it is detrimental to the \\ majority of pupils. In England, no data is routinely recorded regarding these practices, \\ and most research on student outcomes depends on a simplistic dichotomy between \\ pupils grouped and ungrouped by attainment. We present the findings of a survey of \\ attainment grouping practices in English secondary schools, providing an updated \\ picture of the profile of attainment grouping in English and mathematics for students \\ aged 11-16. Grouping in sets is dominant for mathematics and, while variants on mixed \\ attainment grouping are frequently used for students aged 11-14 in English, the \\ frequency of setting increases as students progress through secondary school. Schools \\ with disadvantaged intakes are more likely to group by attainment. We also find that \\ grouping practices are much more complex and dynamic in enactment than is implied \\ by much of the literature and that teachers report that many schools adapt grouping \\ strategies to meet the perceived needs of different cohorts. We provide an updated \\ conceptualisation of grouping practices as a continuum. We conclude the paper by \\ discussing the implications of our findings for interpretation of the current literature on \\ the impact of grouping, as well as implications for future research.
}

Keywords: attainment grouping, ability grouping, secondary schools, setting, streaming

\section{Introduction}

Grouping students by attainment for teaching is a common practice across the world. Approaches include grouping students into different schools based on prior attainment or a notion of aptitude for different types of education; grade retention, where students repeat a school year if their first attempt has been unsuccessful; between-class grouping, where students are grouped by attainment or a notion of ability into different tracks or sets within a school; and within-class grouping where students are regrouped within mixed attainment classes (OECD, 2016). Grouping by attainment engenders strong views among practitioners both for and against the practice (Michaela Community School, 2015). Proponents argue, for example, that placing pupils in attainment groups enables teachers to set lessons at an 
appropriate level, whilst critics highlight the potential damage to low attaining pupils' selfesteem of self-confidence and the difficulty of setting sufficiently high expectations to pupils in low sets (Muijs \& Dunne, 2010).

The focus of this paper is between-class grouping by attainment (known as setting or tracking) within schools in England, where the use of setting is high compared to other systems internationally (OECD, 2016). Typically, this is referred to as 'ability grouping', thus conflating prior attainment with future potential (Francis et al., 2017a).

\section{Background}

Historically, in England, streaming and between-school grouping were commonplace. When the need for mass education was initially acknowledged in England in the mid $19^{\text {th }}$ century, pupils were grouped between schools along social class lines with separate provision for the upper, middle and working classes. In the first half of the $20^{\text {th }}$ century, emerging ideas about intelligence, measurable ability and eugenics were used as justifications to continue to segregate children into different schools, again largely along class lines (Gillard, 2008). This was consolidated in the 1944 Education Act, which established the Tripartite system of grammar, technical and secondary modern schools. Despite the move to comprehensivisation of secondary schools in the 1960s, streaming and setting were still the dominant practice. Even though 'mixed ability' teaching increased in popularity in secondary schools in this period, by the end of the 1970s it was still only commonly practised in the first few years of secondary school, and then in arts and humanities subjects - mathematics and languages remained resistant (Reid, Clunies-Ross, Goacher, \& Vile, 1981). A backlash against mixed attainment teaching developed in the 1980s and 1990s, fanned by criticisms of 'progressive' teaching, yet the practice persisted, particularly in Years 7 and 8 (Kutnick et al, 2005). From 1997 onwards, the Labour White Paper Excellence in Schools '[made] the presumption that setting should be the norm in secondary schools' (DfEE, 1997, 38). Setting remained the 
favoured approach through the Conservative-Liberal Democrat Coalition Government of 2010-2015, with OFSTED (2013) criticising the use of 'mixed-ability teaching' and the Secretary of State for Education Nicky Morgan briefly considering forcing all schools to adopt setting (Wintour, 2014). Since 2015, the policy focus in England has shifted to increasing the number of academically selective schools (e.g. May, 2016).

The impact of attainment grouping on pupils has been the subject of extensive research in England and elsewhere and a large number of literature reviews and metaanalyses synthesise the findings of this research. While not the focus of the present paper, it is important to note that the issue of attainment grouping remains controversial because, in contrast to accepted wisdom amongst politicians and practitioners (Francis et al., 2017a; Wilkinson \& Penney, 2014), these syntheses suggest that attainment grouping has no overall benefit to academic attainment, with a small negative, or zero, impact for low-attaining groups and a small benefit for high attaining pupils (Higgins et al., 2018; Rui, 2009; Slavin, 1990; Steenbergen-Hu, Makel, and Olszewski-Kubilius, 2016). Studies have also found a relationship between pupil self-confidence and attainment grouping (Houtte, Demanet, \& Stevens, 2012; Ireson and Hallam, 2009). Our earlier study found that pupils in lowerattaining groups had lower subject and general self-confidence than their peers in highattaining groups (Francis et al., 2017b), and that the gap in self-confidence between high and low attaining pupils widened over time (Francis et al., 2020).

Notwithstanding, many school leaders believe that within-school grouping has benefits for all pupils, including those with low prior attainment. Indeed, in a study conducted in England, Macleod, Sharp, Bernardinelli, Skipp, and Higgins (2015) found that more than a third of schools surveyed had 'introduced or improved' setting as a way of raising attainment for disadvantaged students. Typically, teachers argue that attainment grouping facilitates 
greater pedagogical and curricular differentiation, allowing pupils' individual needs to be met (e.g. Hallinan, 1994; Rosenbaum, 1999).

\section{The prevalence of grouping by attainment}

The prevalence of within-school grouping appears to be increasing in many countries. Loveless (2013) found that, in the United States, tracking has been consistently used in around three-quarters of eighth grade mathematics classes over nearly three decades, but, having declined in the 1990s has started to increase again in English Language Arts (from $32 \%$ in 1998 to $43 \%$ in 2003). In Germany, as between-school grouping has declined, streaming and tracking have increased (Becker, Neumann, and Dumont, 2016). The PISA survey in 2015 revealed that $38 \%$ of students in OECD countries attend schools where between-class grouping is used for at least some subjects, and $8 \%$ of students attend schools where between-class grouping is used for all subjects. Between 2006 and 2012, there was an overall increase of $1.1 \%$ in the percentage of students grouped into different classes. The largest increase was in Hong Kong (43\%), in contrast to large decreases (over 20\%) in Brazil, Romania and Korea. Furthermore the OECD reports that grouping for specific subjects became more common between 2006 and 2015, with a 4\% increase overall (OECD, 2016). In England a similar rise in attainment grouping is reported at both secondary school (Macleod et al., 2015; Stewart, 2013) and primary school level (Bradbury, 2018; Hallam and Parsons, 2013).

Grouping by attainment is not, however, a universal practice across international educational systems. In Norway, for example, 'permanent' ability grouping is not permitted by law and the vast majority of pupils are taught in mixed attainment classrooms with a culture of inclusion (Fasting, 2013). Indeed, Jerrim's (2019) analysis of TIMSS and PISA data indicates several systems in which a very small proportion of students are grouped by attainment. 
In England, where 'ability' is a 'central working concept' for teachers (Stables et al., 2018), a variety of between-class attainment grouping practices is used in secondary schools. These include setting, where students are grouped by subject attainment for teaching in that subject; streaming, where students are grouped by general ability for teaching across several subjects, and mixed attainment grouping, in which students are grouped such that there is a broad range of prior attainment in each group (Ireson \& Hallam, 2001). In addition to any of the above, some secondary schools use 'within-class grouping' (Marks, 2013; Slavin, 1990) where students are grouped by attainment within the classroom. This is frequently practised in primary schools (Bradbury and Roberts-Holmes, 2017; Towers et al., 2019) and new evidence from PISA suggests a high prevalence in UK secondary schools (OECD, 2020).

However, the exact prevalence of each of these different practices in English secondary schools is difficult to establish. Evidence from the Millennium Cohort Study (MCS) about attainment grouping in primary schools indicates that, in 2008, 37\% of Year 2 (age 6-7) pupils were placed in sets for either literacy or numeracy (Hallam and Parsons, 2012), whilst Hartas's (2018) analysis of the 2012 MCS wave, suggests that, by Year 6 (age 10-11), the final year of primary school, almost all pupils were placed in sets for English and mathematics. Unfortunately, however, the later waves of the MCS study did not collect data about attainment grouping in secondary schools. Dunne and colleagues, investigating schools working with disadvantaged cohorts, found that all 44 secondary schools in their sample taught mathematics to set groups in Years 7-11 (ages 11-16). [ENDNOTE 1] Over half of their sample taught Year 7 and Year 8 students English in set groups, rising to over threequarters in Year 10 (Dunne et al., 2007). However their sample is not representative and may not reflect practice nationally.

OFSTED data from 2001-02 and 2003-04 indicate that fewer than 5\% of schools streamed their students, while across all subjects setting increased from $26 \%$ in Year 7 to 
$44 \%$ in Year 9, with students grouped in sets in up to $83 \%$ of schools for mathematics and $48 \%$ of schools for English (cited in Kutnick et al., 2005, pp. 7-8). These data indicate that at that time setting in mathematics increased with age from 53\% of schools in Year 7 to $100 \%$ in Year 10 and setting in English increased from 34\% in Year 7 to 63\% in Year 10. However, not only is this evidence dated, but it is based on OFSTED inspections in these years and, like Dunne et al. (2007), may not be representative.

More recent data from PISA reinforce this view of 'ability grouping' [ENDNOTE 2] as the predominant practice in the UK, although they do not permit a granular analysis of the types of attainment grouping used or whether schools used streaming or adopted some partial attainment grouping practices, such as the use of nurture groups for low attaining students. Well over $95 \%$ of UK headteachers surveyed in 2012 reported that 15 year-old students (Year 11) were taught in ability-grouped classes for mathematics (OECD, 2013). In 2015, 100\% of UK headteachers surveyed reported that 15 year-old students were taught in ability-grouped classes for 'some subjects' (OECD, 2016). While this survey did not ask headteachers to specify which subjects used ability grouping, it has long been the case that the subjects with the strongest commitments to attainment grouping are mathematics and modern foreign languages (Reid et al., 1981), and our own research has found that mathematics departments are particularly resistant to relinquishing this approach (Taylor et al., 2017).

Overall, it seems plausible that attainment grouping is the dominant practice in secondary schools, in mathematics at least, although the actual extent is not known. The absence of routine administrative data collection or large-scale research in this area means that there is very little known about subjects other than mathematics (a notable exception being Wilkinson et al.’s (2016) investigation of grouping practices in physical education). Similarly, little is known about the grouping of students across secondary school (in Years 710 ), or indeed about the specific types of grouping employed by schools. 


\section{Conceptualising attainment grouping}

Moreover, previous research has not been sufficiently nuanced to capture the complexity and range of grouping practices used in schools, instead characterising them as a simplistic dichotomy between mixed attainment and setting. We have frequently encountered variations on common practices in England during our research, for example mixed attainment grouping with a separate bottom or 'nurture' group, mixed attainment grouping with a separate top group (sometimes known as 'stretch' or 'grammar stream' groups). Furthermore, some schools describe their practices as 'mixed attainment' while having a broad 'mixed middle' as well as separate top and bottom groups (Taylor et al., 2017, 2019). Indeed, our experience of recruiting a large number of schools for an educational trial suggests that these 'partially mixed' variants are being used in a relatively large proportion of schools. Large-scale survey research such as PISA or the Millennium Cohort Study (MCS) does not detect these subtleties in grouping type, as questions about grouping are simplistic with just two or three options for type of grouping. For example, MCS Age 7 Sweep (Wilson, 2008) distinguishes only between streaming, setting and within-class grouping and the 2012 PISA survey distinguishes between no ability grouping, ability grouping for some classes and ability grouping for all classes (Tan and Dimmock, 2020).

Other research has acknowledged that there is diversity of practice, for example Steenbergen-Hu et al. (2016) observe that a variety of terms is used for attainment grouping and that this is a challenge for researchers examining this area. Domina et al.'s (2019, p297) empirical study of student course enrolments identified five 'dimensions of tracking' in the US context:

(1) Degree of curricular differentiation

(2) Classroom skills homogeneity

(3) Track exclusiveness 
(4) Track stability

(5) Track scope

Domina and colleagues note that these dimensions can vary independently, so one school might have a highly differentiated curriculum but be relatively non-exclusive, while another school might be highly exclusive (a high proportion of pupils are in lower tracks), yet have narrower track scope. A further level of complexity is added because understandings of grouping/tracking practices may vary between individuals within schools (Watanabe, 2006).

Differences between the US and English school contexts do not permit Domina et al's conceptualisation to transfer directly to English schools, but some parallels can be drawn. While US middle school pupils may follow different courses in different tracks, in England curricular differentiation is less stark, partly due to a more universal entitlement allowed by the National Curriculum, with the majority of students following the same curriculum to age 16 in most subjects (albeit with two assessment tiers at age 16 in mathematics) (Brown, 2011). Many teachers in England cite increasing classroom skills homogeneity as a goal of attainment grouping (e.g. Kutnick et al., 2005), however there is some doubt as to whether this is achieved (Connolly et al., 2020). Domina and colleagues measure track exclusivity by the percentage of students allocated to lower tracks. In England the numbers of pupils in the very lowest groups are generally small (Dunne et al., 2011) but the number of groups overall varies widely, as does the distribution of pupils at different levels (Connolly et al., 2020; Taylor et al., 2019). Track stability transfers well to the English context: the extent to which pupils stay in the same level of group over time. Track scope also transfers well, reflecting the extent of streaming over setting or mixed attainment grouping (although in the US context broader scope of tracking is de facto rather than planned as in the case of streaming in England). 
We have previously proposed a spectrum of attainment grouping based on prior literature and our own research (Figure 1, Francis et al., 2020), which conceptualises grouping as a continuum from 'Hard' grouping such as between-school segregation, to 'Soft' types such as setting for just one or two subjects. This conceptualisation focuses on Domina's dimensions of classroom skills homogeneity and track scope (noting the distinction between track scope in the US and UK), although Francis and colleagues would dispute that homogeneity of skills is achieved in attainment grouping, arguing instead that grouping is often a system of sorting pupils based on demographic characteristics (Francis et al., 2017a). Francis et al.'s spectrum is concerned with the impact of grouping on pupils, particularly the extent to which it contributes to labelling and a self-fulfilling prophecy (Francis et al., 2020). Hence, 'hard' grouping types offer greater segregation, more rigid labelling and less flexibility for pupils to move between groups, while 'soft' grouping types provide opportunities for much more mixing of students. 'Harder' grouping types are associated with less socially just outcomes.

Figure 1. Attainment grouping spectrum (from Francis, Taylor \& Tereshchenko, 2020, p12).

\begin{tabular}{|c|c|c|c|c|c|}
\hline 'Hard' & & & & 'Soft' & None \\
\hline $\begin{array}{l}\text { Setting with } \\
\text { elements of } \\
\text { streaming }\end{array}$ & $\begin{array}{l}\text { Between- } \\
\text { school } \\
\text { segregation }\end{array}$ & $\begin{array}{l}\text { Streaming including } \\
\text { setting within streams }\end{array}$ & $\begin{array}{l}\text { Setting } \\
\text { 'Ability' tables } \\
\text { just for certain } \\
\text { subjects }\end{array}$ & $\begin{array}{l}\text { Setting for } \\
\text { just one or } \\
\text { two } \\
\text { subjects }\end{array}$ & $\begin{array}{l}\text { Mixed- } \\
\text { attainment } \\
\text { grouping }\end{array}$ \\
\hline & & $\begin{array}{l}\text { Fixed 'ability' tables } \\
\text { consistent across the } \\
\text { school day. }\end{array}$ & & & \\
\hline
\end{tabular}

\section{Contribution made by our research}

The research literature provides very little empirical evidence to support the spectrum proposed above and sheds little light on the prevalence of each of these practices, what sort of 
schools deploy them and why. Improving our understanding of the diversity of grouping practices has a number of benefits. Where existing research has depended upon simplistic categorisation of grouping practices, there is a risk that incorrect conclusions about the impact of grouping types have been drawn. Improved understanding of grouping types facilitates better research designs, taking into account the reality of how grouping is enacted in schools. As noted by Domina et al. (2019 p 315), 'many recent quantitative studies considering individual track locations likely obscure important organisational variation in track practices and their consequences.' Furthermore, a more sophisticated understanding of grouping types provides us with a better basis for understanding the mechanisms that underlie the effects of different forms of attainment grouping.

The study reported here addresses these gaps by using the findings from a national survey to present systematic evidence of the range of attainment grouping practices currently in use in English, mathematics and other subjects in non-selective, state-funded secondary schools with students aged 11-16 in England. In addition, our study moves beyond the dichotomy between mixed attainment and setting, by providing a more nuanced analysis and characterisation of attainment grouping practices than is currently available in the literature. In doing so, we evidence and extend Francis et al.'s (2020) spectrum by mapping the complexity of attainment grouping across the secondary school years. Furthermore, we investigate the relationships between school characteristics and attainment grouping and explore the extent to which schools plan to adhere to the same grouping practices over time.

\section{Method}

\section{The design and administration of the survey}

The research questions were addressed through a survey administered using the platform Online Surveys targeted at subject leaders in English and mathematics. [ENDNOTE 
3] The survey was designed and piloted by the authors. Ethical approval was gained from UCL Institute of Education Research Ethics Committee prior to the start of the research, with approval number REC 1092 and data protection reference Z6364106/2018/05/94. Teachers were required to give their informed consent before completing the survey.

The survey was distributed by email on two occasions to all mainstream state-funded secondary schools in England, excluding grammar schools, 3105 schools in total, with a request that the message and link be forwarded to the Heads of both English and mathematics. The survey was also widely publicised on Twitter and on the Education Endowment Foundation mailing list, as well as being promoted by members of the research team at speaking engagements during the period it was open. The survey remained open for the month of June 2018. Respondents were incentivised through the opportunity to be entered into a draw to win one of $50 £ 25$ Amazon vouchers.

Teacher surveys rarely achieve sufficiently high response rates to be representative and, hence, our analysis uses post-stratification weighting to correct for any imbalances. Nevertheless, as a further check, we conducted a power analysis to calculate the minimum sample size needed to detect a proportion of schools adopting mixed attainment grouping of $15 \%$, an estimate based on our own and others' previous research. Given the population of 3,105 schools, in order to estimate a population proportion of $15 \%$ with a margin of error of $5 \%$ and a standard confidence level of $95 \%$, a power calculation shows that we would require a minimum sample of at least 185 in each of English and mathematics.[ENDNOTE 4] This would mean the sample would be larger than the sample of schools in either of the international surveys, PISA, 170 schools, or TIMSS, 150 schools at Year 9 (Greany et al., 2016; Sizmur et al., 2019).

Respondents provided their school name and postcode, their role at the school and length of time working there. Respondents who identified themselves as English, or 
mathematics, teachers or subject leaders were asked about current and future plans for grouping in English or mathematics, respectively, for each of the school years 7 to 11 (age 11 to 16). Respondents who identified themselves as senior leaders or administrators were asked about both subjects. Questions about current practices were multiple choice with optional free text questions about their current grouping practices. Respondents were also asked whether they were considering changing their grouping practices and, if respondents answered 'yes', they were invited to give more information about their plans in an optional free text response. The full survey is available from the authors. All respondents were asked about grouping in subjects other than English and mathematics.

\section{The sample of schools}

A total of 1,341 responses were collected. After the first data cleaning process, 855 cases were dropped as they did not provide a valid postcode, [ENDNOTE 5] 37 because they were from academically selective (grammar) schools, five because they were from institutions that offered only primary education and four because they were not-state funded. The remaining 440 cases presented valid information. Of these, 65 cases correspond to cases where more than one member of staff from a school answered the questionnaire for either English or mathematics. In these cases, for each subject, the subject leaders' responses were retained. In the case of two subject leader responses for a subject, the respondent with longer tenure or a more complete answer was retained. This resulted in 197 cases for mathematics and 186 cases for English, each above our minimum ideal sample of 185. Additionally, the questionnaire also inquired about current grouping practices in subjects other than English and Mathematics. This information was requested to all the respondents regardless of their role or teaching subject. A total of 375 schools reported valid information, but the number of responses varies through the analysis by subject (as not every respondent had to answer all the questions). 
Table 1 shows descriptive statistics for the schools $(n=375)$ participating in our survey and allows comparing the achieved sample to the national level distribution $(n=3,136)$ of eligible schools in a range of relevant characteristics. [ENDNOTE 6] The survey data was augmented with further data from administrative records (school general information database, school census information, OFSTED rating and student performance information). Based on the postcode provided by the respondents, the unique reference number (URN) for each school was recovered. This variable served for merging the survey information with all the other data extracted from administrative records, with the exception of information about the degree of rurality of the Local Authority (LA), which was merged with data from the 2011 National Census (DEFRA, 2017) using the LA code. After data merge, the original variables were recoded to facilitate the interpretation of the data.

Table 1. Characteristics of participating schools.

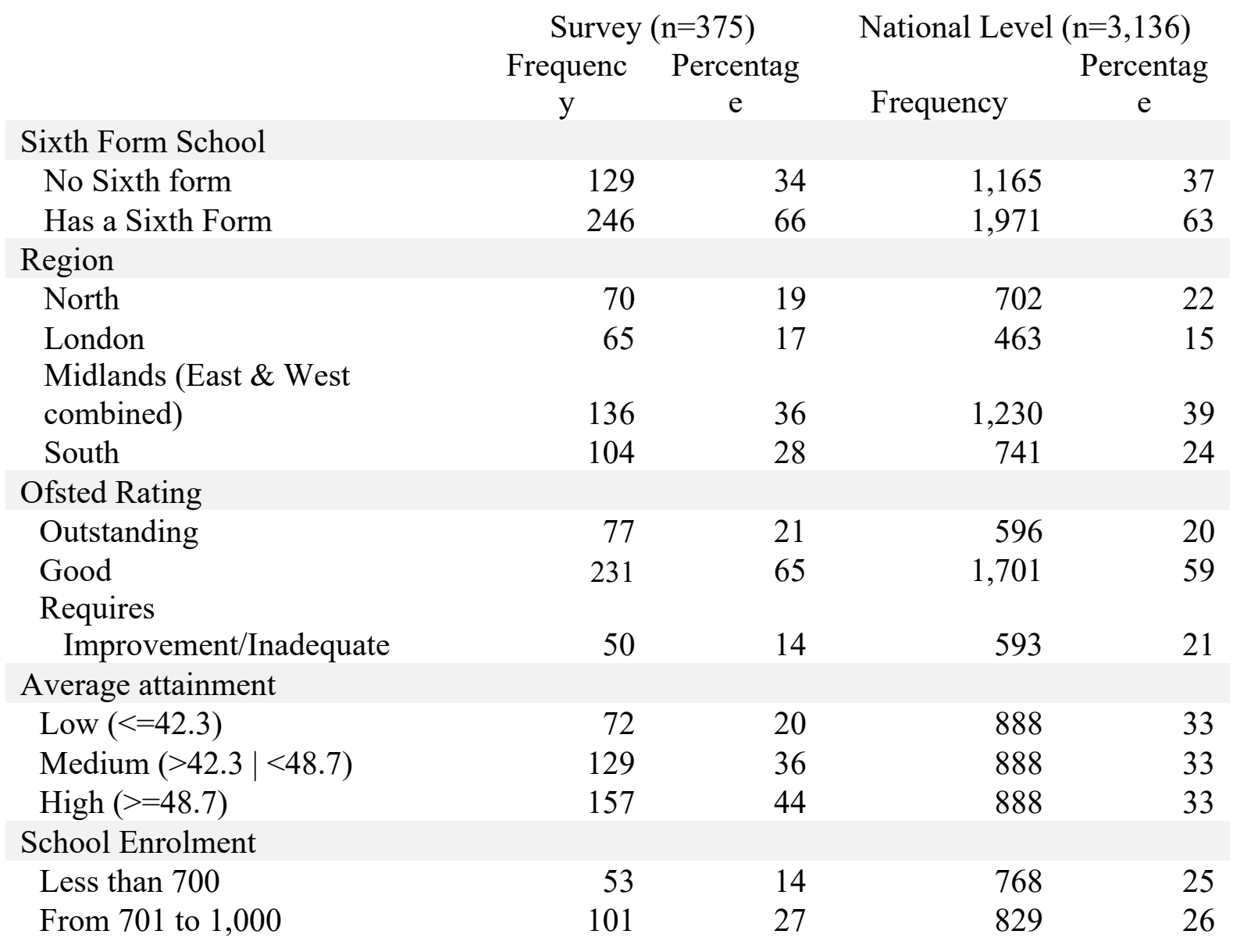


More than 1,000

Free School Meal (FSM)

proportion

Low $(<=20.7 \%)$

Medium $(>20.7 \% \mid<35.4 \%)$

High $(>=35.4 \%)$

Urban-Rural

Predominantly Rural

Predominantly Urban

Mixed

English as an Additional Language (EAL) proportion

Less Than 10\%

From $10 \%$ To $25 \%$

More Than 25\%
221

138

120

117

35

169

171
59

1,539

49

57

$77 \quad 21$

$85 \quad 22$

37

32

31

$$
9
$$

45

46

9

330

1,551

1,255

972

967

965

33

11

49

40

Note: Variables regarding 'Attainment' and 'Free School Meals' were initially constructed using three equal groups at the National Level. The Progress 8 outcome measure was used for attainment. For certain variables, the number of observations may be less than 3,136 cases due to missing information in the original records.

Compared to all eligible English schools, the sample is balanced in several dimensions, such as the geographic location and the proportion of schools with a sixth form. Some imbalance is observed in the schools' enrolment size, with an overrepresentation of large schools; in OFSTED rating, with the respondents of the survey being more likely to be classified in the lower categories; and in levels of attainment at intake, with schools with a low level of average attainment underrepresented compared to the national level and those with high attainment are overrepresented. To account for these differences, weights were used throughout the analysis. The estimates were adjusted considering the prevalence of specific attributes in the universe of eligible schools. Specifically, this procedure attempts to reduce the effects of the non-response bias observed in three variables: the school type, the level of enrolment and the OFSTED Classification. Weights were using a poststratification procedure considering the size of the stratum (being each of them a combination of the three aforementioned variables). Detailed information about the size of the stratum is available as supplementary material. 
The achieved sample, 197 schools in mathematics and 187 in English, is greater than the minimum that we aimed for and represents an acceptable response rate for a survey of this type with teachers. Nevertheless, in order to triangulate and provide further validation of the findings, we collected additional data via the National Foundation for Educational Research (NFER) Teacher Voice Omnibus Survey, a regular survey based on a panel of 1000 teachers (500 from secondary) from a nationally representative sample of schools. [ENDNOTE 7] The results, based on the same survey items but only focused on Years 7-9, were broadly similar across the surveys. See supplementary material for the results of this additional survey.

\section{Analysis of survey responses}

Respondents were asked to report their school's current grouping practices for English and/or mathematics, for each of school years 7-11. Responses were collapsed into five categories: completely mixed, partially mixed, sets, streams and other. These are summarised in Table 2.

Table 2. Attainment grouping types as presented in the survey and as used in the analysis.

\begin{tabular}{ll}
\hline Category & Options as presented in the survey \\
mixed & All English/mathematics teaching groups include children from the \\
full attainment range for the year group. & \\
\hline Partially mixed & Mixed attainment classes with a top set: The highest attaining students \\
& are taught in a separate group for English/mathematics. All other \\
& groups include children from the remaining full attainment range. \\
& Mixed attainment classes with a bottom set or nurture group. The \\
& lowest attaining students are taught in a separate group for
\end{tabular}


English/mathematics. All other groups include children from the remaining full attainment range.

Mixed attainment classes with a top and bottom set. The highest and lowest attaining students are taught in separate groups for English/mathematics. All other groups include children from the remaining full attainment range.*

Sets Students are grouped by attainment in English/mathematics.

Streams Students are grouped for most or all subjects, including

English/mathematics, by a general measure of ability.

\section{Other}

* While superficially 'Mixed attainment classes with a top and bottom set' is analogous to setting in that there are three distinct levels of attainment, we categorise it as 'Partially mixed' because our conversations with schools (see Taylor et al., 2017) lead us to understand that where this approach is used, schools' intentions are more aligned with mixing than setting.

The main results on schools' grouping practices are reported without weighting by school characteristics. However, the estimates were confirmed by using weights (based on School type, Enrolment, and OFSTED Rating) to correct for the potential bias associated with the over/under representation of some schools' features. [ENDNOTE 8]

The relationships between school characteristics and different grouping practices were analysed using weights and Pearson correlation. For each pair of variables (e.g. Grouping practices/School type), the independence between them was tested and the $p$-values for the associations are reported. A summary of these results is available in supplementary material. We were mindful of the potential for Type I errors due to multiple testing, but considered an 
adjustment such as Bonferonni to be too conservative (McDonald, 2014). Instead, using graphical representations, we report associations that are consistently statistically significant across different year groups.

Participants' open-ended responses were coded according a simple structured coding system that was developed on the basis of previous work (Taylor et al., 2017; Taylor et al., 2019) according to whether respondents referred to ability, gender, high attainers, low attainers / nurture groups, provided a justification for their approach or provided other details. Coding was carried by one author, then moderated by three other authors.

Responses to the open questions were coded according to the future grouping strategy being considered. Responses were coded to the first four categories where the change was unambiguous. The changes do not necessarily affect all year groups and some may remain unchanged. Complex changes were coded as 'other'. Categories are summarised in Table 3.

Table 3. Coding table for changes in attainment grouping.

\begin{tabular}{ll} 
Grouping strategy & Description \\
\hline Completely mixed & $\begin{array}{l}\text { Moving to completely mixed attainment for some or all year groups } \\
\text { from sets, partially mixed, streams or other categories. }\end{array}$ \\
\hline Partially mixed & $\begin{array}{l}\text { Moving to partially mixed attainment for some or all year groups } \\
\text { from sets, completely mixed, streams or other categories. }\end{array}$ \\
\hline Sets & $\begin{array}{l}\text { Moving to sets for some or all year groups from partially mixed, } \\
\text { completely mixed, streams or other categories. }\end{array}$ \\
\hline Streams & $\begin{array}{l}\text { Moving to streams for some or all year groups from partially mixed, } \\
\text { completely mixed, sets or other categories. }\end{array}$ \\
\hline Other & $\begin{array}{l}\text { Complex changes such as banding and setting within bands, } \\
\text { introducing different practices in different year groups or grouping } \\
\text { by gender or other factors not related to attainment. }\end{array}$ \\
\hline No change & $\begin{array}{l}\text { Comment does not describe a change from one grouping practice to } \\
\text { another, but may describe modifications to the current practice. }\end{array}$ \\
\hline Does not specify & Changes not specified or not described. \\
\hline
\end{tabular}

\section{Results}

\section{Current grouping practices in mathematics, English and other subjects}

\section{Mathematics:}


In Mathematics, the majority of schools group students in 'Sets' (see Table 4). The prevalence of this approach increases as students progress through the school, from $60 \%$ in Year 7 to $88 \%$ in Year 11. In Year 7, just over a quarter of schools use fully or partially mixed attainment groups, dropping to only $6 \%$ in year 11 . Almost two-thirds of schools (63\%) implement the same grouping practices across all the year groups.

Table 4. Frequencies of attainment grouping types in mathematics, by year group.

\begin{tabular}{cccccc}
$\begin{array}{c}\text { Year } \\
\text { group }\end{array}$ & $\begin{array}{c}\text { Completely } \\
\text { Mixed }\end{array}$ & $\begin{array}{c}\text { Partially } \\
\text { Mixed }\end{array}$ & Sets & Streams & Other \\
\hline Year 7 & 8 & 18 & 60 & 10 & 5 \\
Year 8 & 4 & 13 & 72 & 5 & 4 \\
Year 9 & 2 & 10 & 80 & 4 & 3 \\
Year 10 & 0 & 7 & 85 & 3 & 4 \\
Year 11 & 1 & 5 & 88 & 2 & 4 \\
\hline
\end{tabular}

\section{English:}

Compared with mathematics, English shows more variation in the type of grouping practices implemented by secondary schools (see Table 5). Although grouping in 'Sets' is again the most popular practice, it is much less dominant than in mathematics. In Year 7, a third of schools use 'Sets' rising to just over half in Year 11 (compared to $60 \%$ and $88 \%$, respectively, for mathematics). Consequently, mixed attainment is more prevalent in English compared to mathematics. In Year 7, over half $(55 \%)$ of schools use fully or partially mixed attainment groups, dropping to just below two-fifths in year 11. [ENDNOTE 9] A significant proportion of schools (50\%) use the same grouping practice in all year groups in English. Among the schools that implement the same approach in all years, 59\% use 'Sets', 17\% 'Partially mixed' and $15 \%$ 'Completely mixed' groups. 
Table 5. Frequencies of attainment grouping types in English, by year group.

\begin{tabular}{lccccc}
$\begin{array}{c}\text { Year } \\
\text { group }\end{array}$ & $\begin{array}{c}\text { Completely } \\
\text { Mixed }\end{array}$ & $\begin{array}{c}\text { Partially } \\
\text { Mixed }\end{array}$ & Sets & Streams & Other \\
\hline Year 7 & 31 & 24 & 33 & 8 & 4 \\
Year 8 & 28 & 21 & 38 & 9 & 3 \\
Year 9 & 21 & 27 & 44 & 7 & 2 \\
Year & & & & & \\
10 & 14 & 27 & 49 & 6 & 5 \\
Year & 11 & 28 & 52 & 5 & 4 \\
11 & & & &
\end{tabular}

Other subjects:

Respondents were also asked about grouping practices in "other subjects" (i.e. not English or mathematics). Most of the respondents report that some subjects are grouped by attainment (see Table 6). The prevalence of this approach increases with age, whilst the proportion of schools using mixed attainment groups in all subjects decreases with the age from just under a quarter in year 7 to just over $10 \%$ in year 11 . The proportion of schools grouping by attainment in all subjects is relatively stable across the secondary years at around $10 \%$.

Table 6. Frequencies of attainment grouping types for other subjects, by year group.

\begin{tabular}{cccc}
\hline $\begin{array}{c}\text { Year } \\
\text { Group }\end{array}$ & $\begin{array}{c}\text { All other } \\
\text { subjects } \\
\text { Grouped by } \\
\text { Attainment }\end{array}$ & $\begin{array}{c}\text { Some other } \\
\text { subjects are } \\
\text { Grouped by } \\
\text { Attainment }\end{array}$ & $\begin{array}{c}\text { All other subjects } \\
\text { are taught in Mixed } \\
\text { Attainment groups }\end{array}$ \\
\hline Year 7 & 13 & 64 & 23 \\
Year 8 & 14 & 67 & 19 \\
Year 9 & 13 & 72 & 15 \\
Year 10 & 13 & 78 & 9 \\
Year 11 & 13 & 77 & 11 \\
\hline
\end{tabular}




\section{Arguments given for grouping practices}

Around one third (122) of respondents provided further information on their grouping practices. In most cases, they provided details about the implementation of ability/attainment setting in their school, for example:

We split the year group in half by ability. Then have two mixed groups on the lower half of the year and two mixed groups on the upper half of the year ... (Head of English)

Many responses highlighted that teachers believed they were choosing the grouping practices that were most beneficial for their students, i.e. that they could design and implement a good grouping strategy. Eight respondents described specifically 'nurture group' arrangements, designed to support their lowest attaining students, for example:

The nurture group in Year 7 and 8, whilst mainly consisting of lower attaining students is constructed around additional needs. So some students in that group may be higher ability, but have additional needs so that they cannot be in a normal classroom. (Head of Mathematics)

Seven respondents described the influence of gender on setting, for example this school endeavoured to address underachievement through single-gender groups:

Year 11 differs from normal pattern. Due to a significant number of under-attainers, it was decided to operate a gender split for sets. (Head Mathematics)

The above example is just one of six respondents who emphasised that they used grouping strategically to respond to the perceived needs of a particular cohort:

We organise groupings based upon the cohort needs. In year 7 we also have a bottom group. Our 'top' groups are gender specific. (Head of English)

Other respondents reported constraints on their grouping. Seven respondents indicated that grouping in either English or mathematics was influenced (or determined) by grouping 
decisions in other subjects, such as English being timetabled with humanities, or mathematics with science, in line with our previous findings about the complexity of school structures and practices (Taylor et al., 2019):

They are set initially by science (double or triple) and then by ability. The lower groups for double science create their own lower ability cohort in maths. (Head of Mathematics)

Also in line with previous findings, six respondents described how timetabling and other school restrictions affected their grouping decisions, for example:

We are limited in terms of staffing - non-specialists who struggle to differentiate for genuine mixed ability. We strategically place students within sets based on behaviour, targets and attainment. We're trapped by the timetable in Y7 and it means we don't have any flexibility as to how we group students compared to maths who can group in any way. (English)

It is clear from these examples that teachers are trying to use grouping to meet students' needs within the limitations of their school systems.

\section{The characteristics of schools using different grouping strategies}

We investigate this question using the English data, because the overall dominance of 'sets' as a grouping strategy in mathematics means that there are no detectable differences in attainment grouping strategies between schools of different types. Tables showing a breakdown of grouping practices and school characteristics by year group can be found in the supplemental material.

There were no practically important differences in grouping practices amongst schools of different sizes, School Type or those with/without a sixth form, or amongst schools with differing proportions of pupils in receipt of free school meals, with English as an Additional Language or with SEND. Using graphical representations, we report associations 
that are consistent and statistically significant across different year groups: the average level of attainment of students, the region where the schools are located, and the OFSTED classification of the school. Schools with relatively low average attainment were more likely than other schools to use setting or streaming (see Figure 2). This contrast is particularly stark in lower secondary. Schools in the North of England are more likely to use setting or streaming in comparison to other regions (see Figure 3). This may partially reflect that schools in the North are also comparatively low attaining (School Dash, 2019). Finally, schools with an OFSTED judgment of 'Requires Improvement' or 'Inadequate' are more likely to use sets or streams in comparison to those judged to be 'Good' or 'Outstanding' (see Figure 4).

Briefly, we note that this is a different pattern to that found by Domina et al. (2019), who found that school mean prior attainment was associated with less within-class skills homogeneity.

Figure 2. Prevalence of setting and streaming in English by school overall attainment

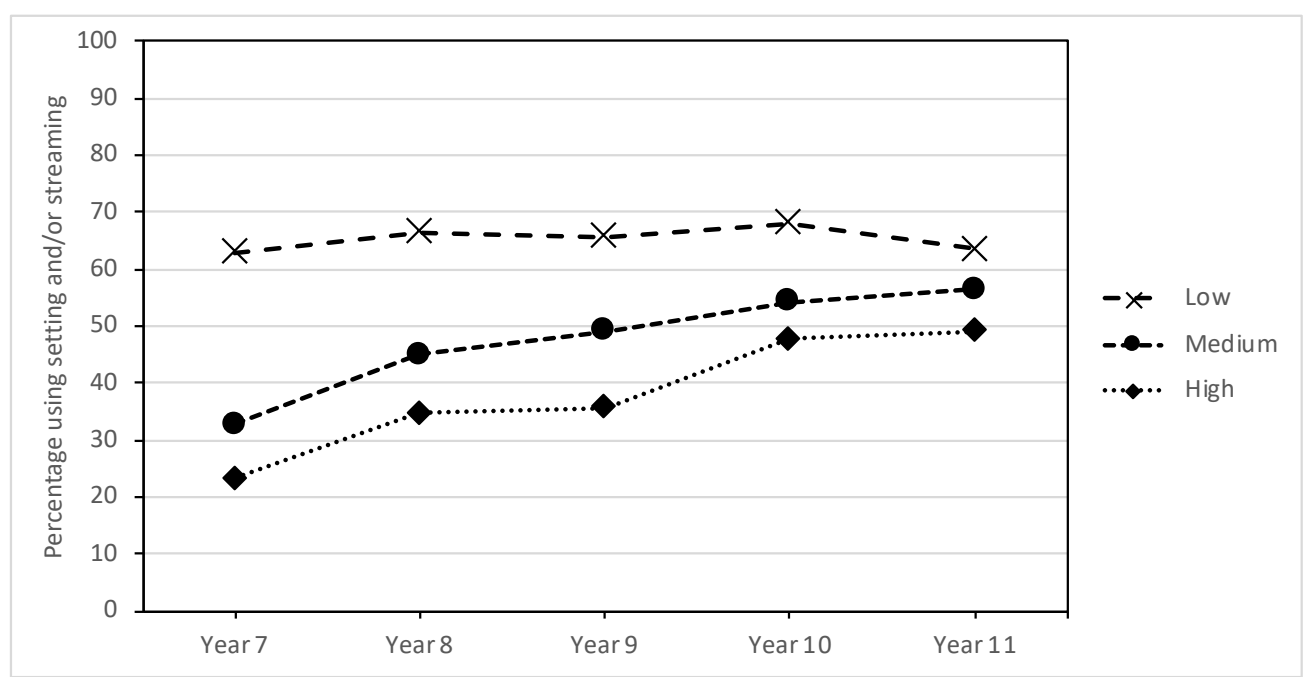


Figure 3. Prevalence of setting and streaming in English by region

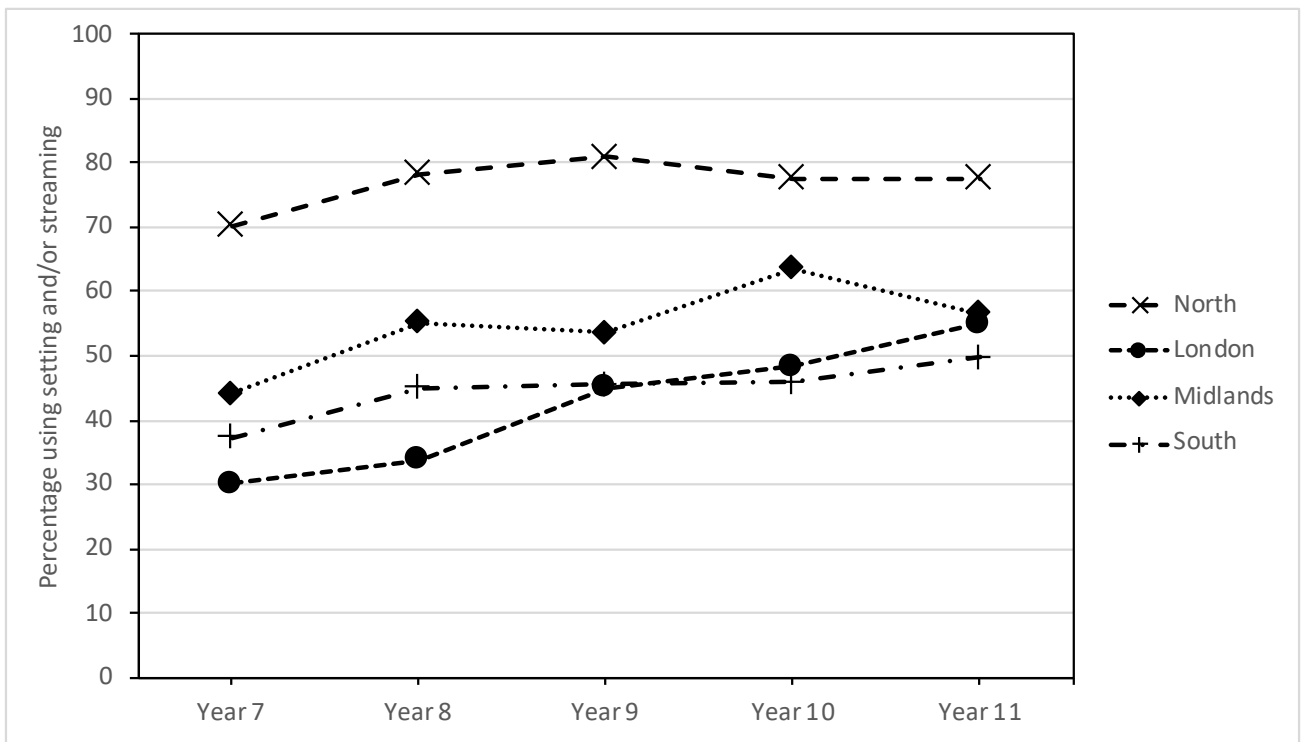

Figure 4. Prevalence of setting and streaming in English by OFSTED category

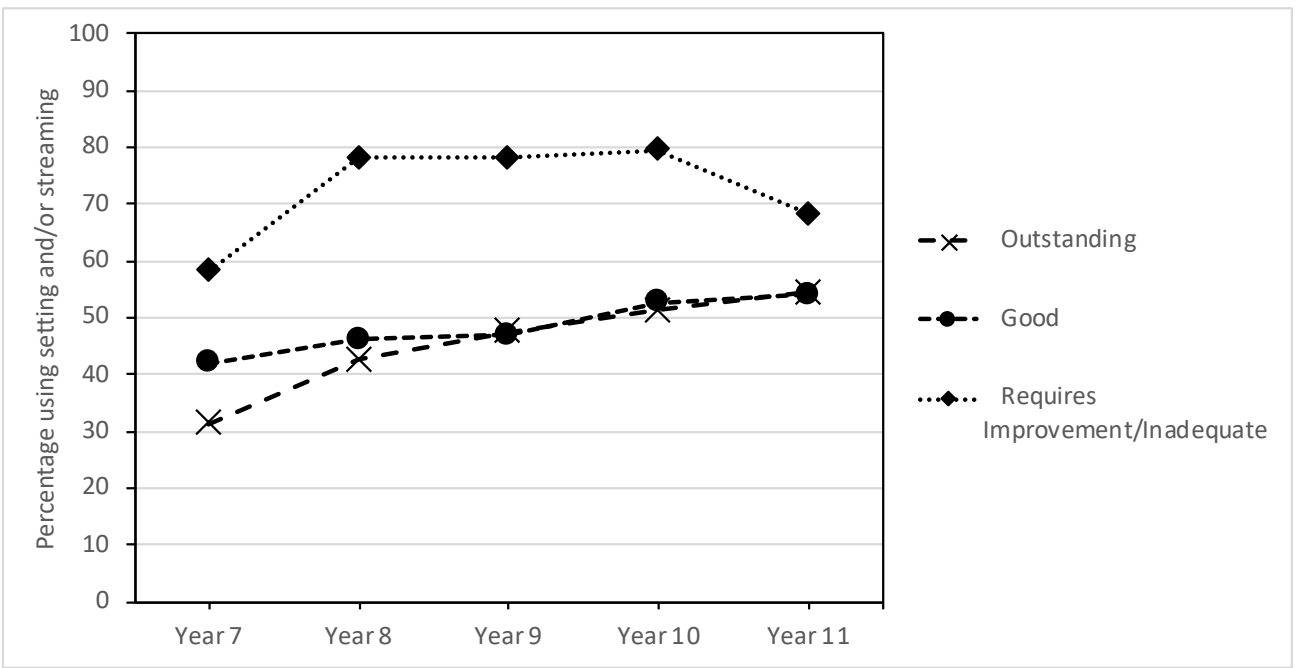

\section{Future grouping practices}

English:

56 respondents $(30 \%)$ stated that they were considering changes to their current grouping practices. There did not appear to be any systematic differences between the schools considering changes to their current grouping practices and those that are not planning any 
changes. Fifty-six of these respondents provided valid comments. These are summarised in Table 7. The majority of these respondents' schools, just under $20 \%$ of the total English sample, were considering moving to partially or completely mixed attainment grouping.

Table 7. Potential changes to current attainment grouping practices in English.

\begin{tabular}{lrrr}
\hline $\begin{array}{l}\text { Potential new } \\
\text { grouping type }\end{array}$ & n (total $=\mathbf{5 6})$ & $\begin{array}{r}\text { Percentage of } \\
\text { respondents }\end{array}$ & $\begin{array}{r}\text { Percentage of total } \\
\text { sample of } \\
\text { respondents in } \\
\text { English }\end{array}$ \\
\hline Partially mixed & 20 & 36 & 11 \\
Completely mixed & 15 & 27 & 8 \\
Sets & 2 & 4 & 1 \\
Streams & 1 & 2 & 1 \\
Does not specify & 4 & 7 & 2 \\
No change & 6 & 11 & 3 \\
Other & 8 & 14 & 4 \\
\hline
\end{tabular}

\section{Mathematics:}

Only 34 respondents $(17 \%)$ reported that they were planning changes in their grouping practices. Thirty respondents provided valid answers, which are summarised in Table 8. In comparison to English, mathematics is more stable and relatively few respondents were considering any form of change.

Table 8. Potential changes to current attainment grouping practices in mathematics.

\begin{tabular}{lcrr}
\hline $\begin{array}{l}\text { Potential new } \\
\text { grouping type }\end{array}$ & $\mathbf{n}($ total $=\mathbf{3 0})$ & $\begin{array}{r}\text { Percentage of } \\
\text { respondents }\end{array}$ & $\begin{array}{r}\text { Percentage of total } \\
\text { sample of } \\
\text { respondents in } \\
\text { mathematics }\end{array}$ \\
\hline Partially mixed & 7 & 23 & 4 \\
Completely mixed & 4 & 13 & 2 \\
Sets & 3 & 10 & 2 \\
Streams & 0 & 0 & 0 \\
Does not specify & 3 & 10 & 2 \\
No change & 7 & 23 & 4 \\
Other & 6 & 20 & 3 \\
\hline
\end{tabular}

Overall, for those schools where a change in grouping in English is being contemplated (around one third of schools), the direction of change is strongly towards 
completely mixed or partially mixed grouping. This is in contrast to the picture suggested from the national and international literature, suggesting an increase in attainment grouping.

Following the finding that setting is the dominant practice in mathematics, there is a similar conservatism in grouping, with mathematics teachers less likely to report that they were considering changing grouping types. However, those who were considering changing grouping practice were more likely to be considering a move towards a form of mixed attainment grouping, or 'other' practices.

\section{Discussion}

Our findings, based on a national survey of English and mathematics subject leaders in non-selective state-funded secondary schools in England, provide evidence that grouping practices are more complex than a simply binary distinction between setting and mixed attainment. Furthermore, we have found empirical evidence that these practices fall within a spectrum of attainment grouping as hypothesised in our previous work (Francis et al., 2020).

We have demonstrated that, contrary to much accepted wisdom (e.g. Kutnick et al., 2005), streaming is still in use; in our survey, by around $10 \%$ of schools at the start of lower secondary education. As predicted, we have found that setting is the dominant attainment grouping practice used in mathematics, although, even in mathematics, it is not universal. As expected, we have found much more variation in English with a substantial proportion of schools, almost 40\%, using either completely or partially mixed attainment at year 11 .

Again, as expected, we have shown that setting is widely practised in subjects other than English and mathematics and that there is an increase in setting and decrease in completely mixed attainment grouping as students progress through secondary education. These proportions are broadly in line with the previous, less robust, estimates from early in the last decade (Kutnick et al., 2005), suggesting that the prevalence of grouping by attainment has not changed dramatically over the past 15 to 20 years. Moreover, our evidence 
is also in line with findings from the PISA survey (OECD, 2013). Further research is needed to provide a more detailed picture of grouping in specific subjects other than English and mathematics, as the present study did not distinguish between 'other subjects'.

However, in contrast to earlier studies, which have implied a simplistic, three-way, distinction between setting, streaming and mixed attainment grouping, we have shown that there is much more variation in practices. We have shown that a significant minority of schools practice 'partially mixed attainment grouping' with students predominantly in mixed attainment groups, but some provision in homogeneous attainment groups for students at one or both extremes of the attainment spectrum. We have also shown that there is variation within practices, replicating our previous finding of variation in implementation of setting, e.g. number of sets, and strategies for set allocation (Taylor et al., 2019).

Our findings lead us to revise our earlier attainment grouping spectrum, to acknowledge the prevalence of partially-mixed grouping types and to stress that partial mixing is not the same practice as fully-mixed attainment grouping (see Figure 5 for the revised spectrum).

Figure 5. Revised attainment grouping spectrum with changes in italics. We note that with subject specific grouping types (setting and partial mixing), the more subjects that they apply to, the 'harder' the attainment grouping. 


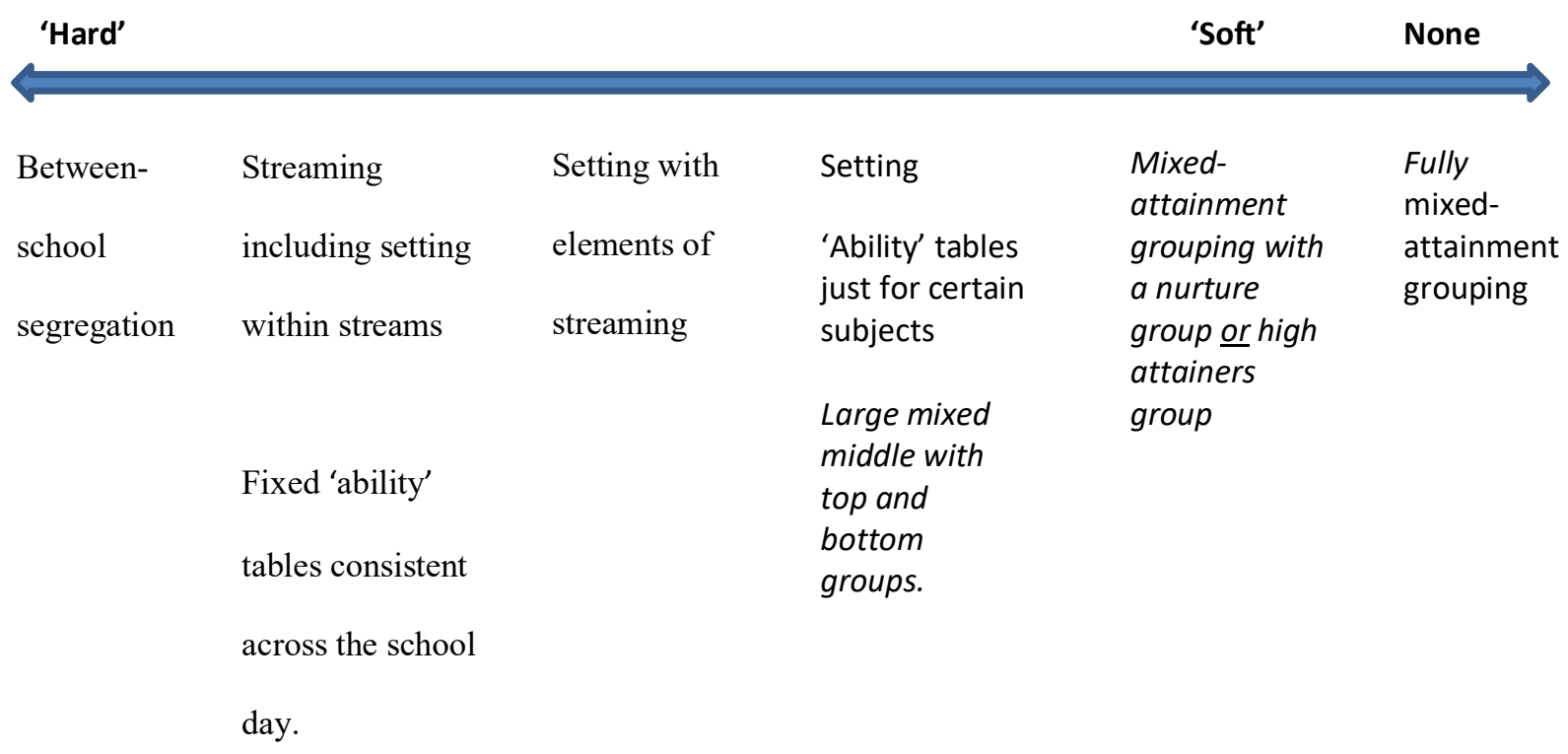

In fact this reinforcement of the complexity of grouping practices is a challenge for the current literature addressing attainment grouping, as it tends to over-simplify the categorisation of grouping types. As noted by Domina et al. (2019) in the US, there is a need for research within the English system that is able to separate out the effects of different aspects of grouping practices.

We have also shown that disadvantaged schools, those with low average attainment, poor OFSTED ratings and those in the North of England (Local Government Association, 2019; School Dash, 2019), are more likely to use attainment grouping. This finding provides additional weight to existing evidence (DFE, 2015) indicating that, despite evidence that grouping by attainment tends to further disadvantage already disadvantaged students, this practice is more, rather than less, likely to be adopted for these students. It is worth emphasising here that we found that teachers and schools indicated that their grouping practices were intended to serve the interests of all their pupils, but their decisions around grouping were made in the context of a strong discourse of 'ability', a discourse that we have argued is dominant within our education system. As a result, in trying to counter educational 
inequities, schools actually increase existing inequities, creating a a 'double disadvantage' (Francis et al., 2017a) for those placed in lower sets.

Our findings also show that some schools are using grouping 'tactically' to respond to the perceived 'ability' profiles of particular cohorts of students. This responsive grouping sometimes results in schools dividing pupils along gender lines, a practice that Martino and colleagues found could result in gender stereotyping of student needs, leading to restricted pedagogies, lowered expectations and less intellectually-demanding lessons for boys (Martino, Mills, and Lingard, 2005). In other cases it results in changes in grouping strategies from year to year, potentially removing the opportunity for teachers to adapt and improve their pedagogy appropriately. As teachers often suffer 'policy fatigue' when changes are imposed from above (Mills and McGregor, 2016) and indeed find implementing pedagogical change challenging (Cuban, 2013), frequent grouping changes may not be a promising approach for improving pupil learning. As discussed earlier almost all children are placed in attainment sets for both English and mathematics in year 6 at the end of primary schooling (Hartas, 2018). This decision is likely to be motivated by a desire to maximise attainment in Key Stage 2 SATs (Bradbury, 2018; Towers et al., 2019), which would benefit both schools and pupils, but is counterproductive in terms of the impact on equity, self-confidence and the attainment of middle- and lower-attaining pupils. It also means that students entering secondary schools using mixed attainment grouping are likely to have already suffered detriment due to earlier grouping experiences.

Finally, in the context of a move towards attainment grouping in schools internationally (e.g. OECD, 2016), we have found a somewhat different picture in England where grouping by attainment has historically been unusually dominant. Where English secondary schools are considering changing their grouping practices, they are most likely to be doing so in English and to be considering moving in the direction of more mixed 
grouping, either 'completely mixed' or 'partially mixed'. Only a few schools are considering changes to grouping practices for mathematics. The move toward mixed attainment grouping in English could be evidence that schools are adopting research-informed practices.

We are optimistic that our research indicates increasing scope for dialogue between researchers and practitioners with regard to grouping practices. Evidence of diversity of practice and willingness to contemplate change, suggests that schools may be open to persuasion from high quality research evidence (such as we hope to generate through our ongoing 'Student Grouping Study' (Hodgen et al., 2019)) to increase the equity of their attainment grouping practices to the benefit of all students.

\section{Notes}

[1] In England, secondary school, the focus of this paper, is compulsory from age 11 to 16 . Year 7 (age 11-12) is broadly equivalent Grade 6 internationally and so on. At age 16, the end of Year 11, almost all students take the General Certificate of Secondary Education (GCSE) in English and mathematics as well as a range of other subjects.

[2] OECD refer to grouping by 'ability' rather than attainment.

[3] www.onlinesurveys.ac.uk

[4] https://select-statistics.co.uk/calculators/sample-size-calculator-population-proportion/

[5] As in many online surveys using monetary incentives, a substantial proportion of the answers were not valid. However, as the survey required specific information about the school name and postcode, those cases were identified and dropped from the analysis. We assumed a conservative approach, and did not include any observation that failed to provide accurate information for identification of the school.

[6] The invitation for taking part in the study was delivered using the Campus Marketing Database $(3,105)$ while the National-Level descriptive statistics were estimated using official administrative records $(3,136)$. Differences in the number of observations between both databases are minor and unlikely to substantially affect the results. 
[7] For further information on the NFER Teacher Voice Omnibus Survey see: www.nfer.ac.uk/keytopics-expertise/products/teacher-voice-omnibus-survey/

[8] The use of weights imposes additional challenges to the sample. As there is some loss of information associated with certain variables used for post-stratification (e.g. 'OFSTED Rating') the number of observations in the original data drops when the weighting procedure is implemented. Therefore, we have opted to begin by presenting the results of the achieved sample without using weights and reserve this procedure for the analysis of the characteristics of the schools implementing the different grouping strategies (Figures 2-4 in the main text and all the analysis in the supplementary material).

[9] Results from the NFER Teacher Voice Omnibus survey confirm our findings, showing, for example, increases in the use of 'Sets' as students progress in the school (34\% in year 7; $40 \%$ in year 8 ; and $46 \%$ in year 9). Full results from the NFER survey are provided as supplemental material.

\section{Acknowledgements}

We are grateful to Professor Matthew Inglis and Professor Andy Noyes for their comments on an earlier draft of the manuscript.

\section{Funding}

This research was supported by the Education Endowment Foundation.

Gabriel Gutiérrez is supported by Associative Research Programme, grant number ANID PIA CIE160007.

\section{Biographical note}

Becky Taylor is Senior Research Fellow in the Centre for Teachers and Teaching Research at UCL Institute of Education, where she leads on the Teaching strand of the Centre's work. She is interested in the relationship between research, policy and practice in schools, with a social justice perspective.

Jeremy Hodgen is a Professor of Mathematics Education at the UCL Institute of Education. He is interested in investigating ways of improving teaching and learning for all learners and conducting research relevant to schools, teachers and policy-makers. He is currently Chair of the British Society for the Learning of Mathematics. 
Antonina Tereshchenko is Research Fellow in the Centre for Teachers and Teaching Research at UCL Institute of Education. She has been involved in four different research projects around attainment grouping in England.

Gabriel Gutiérrez holds a PhD in Education at UCL Institute of Education. He is an ESRCPostdoctoral Fellow at the London School of Economics and Political Science (Department of Social Policy) and an Associate Researcher at the Centre for Educational Justice (Pontificia Universidad Católica de Chile).

\section{References}

Becker, M., Neumann, M., \& Dumont, H. (2016). Recent Developments in School Tracking Practices in Germany: An Overview and Outlook on Future Trends. Orbis Scholae, 3/2016, 9-25.

Bradbury, A. (2018). The impact of the Phonics Screening Check on grouping by ability: A 'necessary evil' amid the policy storm. British Educational Research Journal, 44(4), 539-556. doi:10.1002/berj.3449

Bradbury, A. and Roberts-Holmes, G. (2017). Grouping in Early Years and Key Stage 1: 'A necessary evil'? London: NEU.

Brown, M. (2011). Going back or going forward? Tensions in the formulation of a new National Curriculum in mathematics. Curriculum Journal, 22(2), 151 - 165. doi:10.1080/09585176.2011.574882

Connolly, P., Taylor, B., Francis, B., Archer, L., Hodgen, J., Mazenod, A., and Tereshchenko, A., (2020). The misallocation of students to academic sets in maths: a study of secondary schools in England. British Educational Research Journal, 45 (4), 873-897.

Cuban, L. (2013). Why so many structural changes in schools and so little reform in teaching practice? Journal of Educational Administration, 51(2), 109-125. doi:10.1108/09578231311304661

DEFRA. (2017, 7 November 2017). 2011 Rural Urban Classification. Retrieved from https://www.gov.uk/government/statistics/2011-rural-urban-classification, 21 December 2018.

DfEE. (1997). Excellence in Schools. London: HMSO Retrieved from http://www.educationengland.org.uk/documents/wp1997/excellence-inschools.html, 22 April 2016. 
Domina, T., McEachin, A., Hanselman, P., Agarwal, P., Hwang, N., \& Lewis, R.W. (2019). Beyond tracking and detracking: the dimensions of organizational differentiation in schools. Sociology of Education, 92(3), 293-322.

Dunne, M., Humphreys, S., Sebba, J., Dyson, A., Gallannaugh, F., \& Muijs, D. (2007). Effective teaching and learning for pupils in low attaining groups. London: DCSF.

Dunne, M., Humphreys, S., Dyson, A., Sebba, J., Gallannaugh, F., and Muijs, D., (2011). The teaching and learning of pupils in low-attainment sets. Curriculum Journal, 22 (4), $485-513$.

Fasting, R. B. (2013). Adapted education: the Norwegian pathway to inclusive and efficient education. International Journal of Inclusive Education, 17(3), 263-276. doi:10.1080/13603116.2012.676083

Francis, B., Archer, L., Hodgen, J., Pepper, D., Taylor, B., \& Travers, M.-C. (2017a). Exploring the relative lack of impact of research on 'ability grouping' in England: a discourse analytic account. Cambridge Journal of Education, 47(1), 1-17.

Francis, B., Connolly, P., Archer, L., Hodgen, J., Mazenod, A., Pepper, D., Sloan, S., Taylor, B., Tereshchenko, A., and Travers, M.-C., (2017b). Attainment Grouping as selffulfilling prophecy? A mixed methods exploration of self confidence and set level among Year 7 students. International Journal of Educational Research, 86, 96-108.

Gillard, D. (2008). Us and Them: a history of pupil grouping policies in England's schools. Retrieved from http://www.educationengland.org.uk/articles/27grouping.html, 9 October 2019.

Greany, T., Barnes, I., Mostafa, T., Pesniero, N., \& Swenson, C. (2016). Trends in Maths and Science Study (TIMSS): National Report for England. London: Department for Education.

Hallam, S., \& Parsons, S. (2013). Prevalence of streaming in UK primary schools: Evidence from the Millennium Cohort Study. British Educational Research Journal, 39(3), 514-544.

Hallinan, M.T., 1994. Tracking: From Theory to Practice. Sociology of Education, 67 (2), 79-84.

Hartas, D. (2018). Setting for English and Maths: 11-year-olds' characteristics and teacher perceptions of school attitudes. Research Papers in Education, 33 (3), 393-410. doi:10.1080/02671522.2017.1329338 
Higgins, S., Major, L. E., Coleman, R., Katsipataki, M., Henderson, P., Mason, D., . . Kay, J. (2018). The Sutton Trust-Education Endowment Foundation Teaching and Learning Toolkit. London: Education Endowment Foundation.

Hodgen, J., Taylor, B., Anders, J., Tereshchenko, A., and Francis, B. (2019). The Student Grouping Study: investigating the effects of setting and mixed attainment grouping Study Plan. London: Education Endowment Foundation.

Houtte, M. V., Demanet, J., \& Stevens, P. A. J. (2012). Self-esteem of academic and vocational students: Does within-school tracking sharpen the difference? Acta Sociologica, 55(1), 73-89. doi:10.1177/0001699311431595

Ireson, J., \& Hallam, S. (2001). Ability grouping in education: London: Paul Chapman. Ireson, J., \& Hallam, S. (2009). Academic self-concepts in adolescence: Relations with achievement and ability grouping in schools. Learning and Instruction, 19(3), 201213. doi:http://dx.doi.org/10.1016/j.learninstruc.2008.04.001

Jerrim, J. (2019). England's schools segregate by ability more than almost every other country in the world. Retrieved from https://ffteducationdatalab.org.uk/2019/09/englands-schools-segregate-by-abilitymore-than-almost-every-other-country-in-the-world/, 25 October 2019.

Kutnick, P., Sebba, J., Blatchford, P., Galton, M., Thorp, J., MacIntyre, H., \& Berdondini, L. (2005). The effects of pupil grouping: Literature review. London: DFES.

Local Government Association. (2019). Percentage of secondary school pupils with free school meals in England. Retrieved from https://Iginform.local.gov.uk/reports/Igastandard?mod-metric=2174\&modarea=E92000001\&mod-group=AllRegions England\&modtype=namedComparisonGroup, 9 October 2019.

Loveless, T. (2013). The 2013 Brown Center Report on American Education: How well are American students learning? Washington DC: Brown Center.

Macleod, S., Sharp, C., Bernardinelli, D., Skipp, A., \& Higgins, S. (2015). Supporting the attainment of disadvantaged pupils: articulating success and good practice. London: Department for Education.

Marks, R. (2013). “The blue table means you don't have a clue": the persistence of fixedability thinking and practices in primary mathematics in English schools. FORUM: for Promoting 3-19 Comprehensive Education, 55(1), 31-44. doi:http://dx.doi.org/10.2304/forum.2013.55.1.31 
Martino, W., Mills, M., \& Lingard, B. (2005). Interrogating single-sex classes as a strategy for addressing boys' educational and social needs. Oxford Review of Education, 31(2), 237-254. doi:10.1080/03054980500117843

May, T. (2016). Britain, the great meritocracy: Prime Minister's speech. Retrieved from https://www.gov.uk/government/speeches/britain-the-great-meritocracy-primeministers-speech, 9 October 2019.

McDonald, J. H. (2014). Handbook of Biological Statistics (3rd ed.). Baltimore, ML: Sparky House Publishing.

Michaela Community School. (2015). Mixed Ability Works. Retrieved from https://www.youtube.com/watch?v=YUa Cl-stRo, 9 October 2019.

Mills, M., \& McGregor, G. (2016). Learning not borrowing from the Queensland education system: lessons on curricular, pedagogical and assessment reform. The Curriculum Journal, 27(1), 113-133. doi:10.1080/09585176.2016.1147969

Muijs, D., \& Dunne, M. (2010). Setting by ability, or is it? A quantitative study of determinants of set placement in English secondary schools. Educational Research, 52(4), $391-407$.

OECD. (2013). Selecting and grouping students. In PISA 2012 results: What makes schools successful? Resources, Policies and Practices (Vol. IV, pp. 71-92). Paris: OECD Publishing.

OECD. (2016). PISA 2015 Results (Volume II): Policies and Practices for Successful Schools, PISA, . Paris: OECD Publishing.

OECD. (2020). PISA 2018 Results (Volume V): Effective Policies, Successful Schools. Paris: PISA, OECD Publishing.

OFSTED. (2013). The most able students: Are they doing as well as they should be in our non-selective secondary schools? Manchester: OFSTED.

Reid, M., Clunies-Ross, L., Goacher, B., \& Vile, C. (1981). Mixed-ability teaching: problems and possibilities. Windsor: NFER-Nelson.

Rosenbaum, J.E., 1999. If Tracking Is Bad, Is Detracking Better? American Educator, 23 (4), 24-29, 47.

Rui, N. (2009). Four decades of research on the effects of detracking reform: Where do we stand?-A systematic review of the evidence. Journal of Evidence-Based Medicine, 2(3), 164-183. doi:10.1111/j.1756-5391.2009.01032.x 
School Dash. (2019). Map of England showing regions. Retrieved from https://www.schooldash.com/maps.html, 9 October 2019.

Sizmur, J., Ager, R., Bradshaw, J., Classick, R., Galvis, M., Packer, J., Thomas, D., \& Wheater, R. (2019). Achievement of 15-year-olds in England: PISA 2018 results. London: Department for Education.

Slavin, R. E. (1990). Achievement effects of ability grouping in secondary schools: A bestevidence synthesis. Review of Educational Research, 60(3), 471-499.

Steenbergen-Hu, S., Makel, M. C., \& Olszewski-Kubilius, P. (2016). What One Hundred Years of Research Says About the Effects of Ability Grouping and Acceleration on K-12 Students' Academic Achievement. Review of Educational Research, 86(4), 849-899. doi:10.3102/0034654316675417

Stewart, W. (2013, 5 April 2013). Do setting and streaming work? Times Educational Supplement. Retrieved from https://www.tes.com/article.aspx?storycode=6327587, 19 April 2016.

Tan, C.Y. and Dimmock, C., (2020). The relationships among between-class ability grouping, teaching practices, and mathematics achievement: a large-scale empirical analysis. Educational Studies, 1-19.

Taylor, B., Francis, B., Archer, L., Hodgen, J., Pepper, D., Tereshchenko, A., \& Travers, M.C. (2017). Factors deterring schools from mixed attainment teaching practice. Pedagogy, Culture \& Society, 25(3), 327-345. doi:10.1080/14681366.2016.1256908

Taylor, B., Francis, B., Craig, N., Archer, L., Hodgen, J., Mazenod, A., . . Pepper, D. (2019). Why is it difficult for schools to establish equitable practices in allocating students to attainment 'sets'? British Journal of Educational Studies, 67(1), 5-24. doi:10.1080/00071005.2018.1424317

Towers, E., Taylor, B., Tereshchenko, A., \& Mazenod, A. (2019). 'The reality is complex': Teachers' and School Leaders' accounts and justifications of grouping practices in the English Key Stage 2 classroom. Education 3-13. doi:10.1080/03004279.2019.1569707

Watanabe, M., (2006). 'Some People Think This School Is Tracked and Some People Don't': Using Inquiry Groups to Unpack Teachers' Perspectives on Detracking. Theory Into Practice, 45 (1), 24-31. 
Wilkinson, S.D. and Penney, D., (2014). The effects of setting on classroom teaching and student learning in mainstream mathematics, English and science lessons: a critical review of the literature in England. Educational Review, 66 (4), 411-427.

Wilkinson, S., Penney, D., and Allin, L., (2016). Setting and within-class ability grouping: A survey of practices in physical education. European Physical Education Review, 22 (3), 336-354.

Wilson, S., (2008). Child of the New Century Age 7 Survey: Teacher Questionnaire England [online]. Available from: https://cls.ucl.ac.uk/wpcontent/uploads/2017/07/mcs4_teacher_england.pdf. [Accessed 8 July 2020].

Wintour, P. (2014, 3 September 2014). Compulsory setting: schools face being forced to separate pupils by ability. The Guardian. Retrieved from http://www.theguardian.com/politics/2014/sep/03/schools-separate-pupils-abilitysetting

\section{Supplemental material}

(1) Estimates of grouping types using post-stratification adjustment: Year 7, Year 8, Year 9, Year 10, Year 11

(2) Stratums for weight adjustment

(3) Uncorrected Chi-2 statistics and Chi-2 Pearson correlation between Grouping practices and School-level descriptive variables by school year

(4) Percentage of current grouping practices by Subject: NFER Teacher Voice results, May 2018. 


\section{SUPPLEMENTAL MATERIAL}

Estimates of grouping types using post-stratification adjustment ${ }^{1}$

\begin{tabular}{|c|c|c|c|c|c|c|c|}
\hline \multirow[b]{3}{*}{ Region ** } & \multicolumn{7}{|c|}{ Current practices /English / Year 7} \\
\hline & \multirow{2}{*}{ 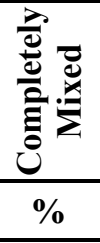 } & \multirow{2}{*}{ 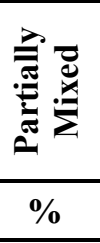 } & \multirow{2}{*}{$\begin{array}{l}\stackrel{\omega}{0} \\
\% \\
\%\end{array}$} & \multirow{2}{*}{ 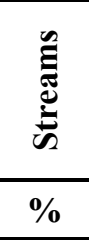 } & \multirow{2}{*}{ 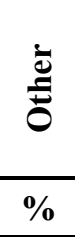 } & \multicolumn{2}{|c|}{$\stackrel{\bar{\pi}}{0}$} \\
\hline & & & & & & $\mathbf{N}$ & $\%$ \\
\hline North & $12 \%$ & $20 \%$ & $65 \%$ & $4 \%$ & $0 \%$ & 23 & $13 \%$ \\
\hline London & $53 \%$ & $14 \%$ & $25 \%$ & $6 \%$ & $2 \%$ & 26 & $15 \%$ \\
\hline Midlands (East \& West) & $29 \%$ & $21 \%$ & $33 \%$ & $11 \%$ & $6 \%$ & 74 & $42 \%$ \\
\hline South & $32 \%$ & $26 \%$ & $33 \%$ & $3 \%$ & $8 \%$ & 54 & $30 \%$ \\
\hline Total & $30 \%$ & $21 \%$ & $37 \%$ & $8 \%$ & $5 \%$ & 178 & $100 \%$ \\
\hline \multicolumn{8}{|l|}{ Urban - Rural ** } \\
\hline Predominantly Rural & $16 \%$ & $28 \%$ & $49 \%$ & $0 \%$ & $7 \%$ & 11 & $6 \%$ \\
\hline Predominantly Urban & $31 \%$ & $19 \%$ & $36 \%$ & $12 \%$ & $1 \%$ & 71 & $40 \%$ \\
\hline Mixed & $31 \%$ & $22 \%$ & $36 \%$ & $5 \%$ & $6 \%$ & 95 & $54 \%$ \\
\hline Total & $30 \%$ & $21 \%$ & $37 \%$ & $8 \%$ & $5 \%$ & 178 & $100 \%$ \\
\hline \multicolumn{8}{|l|}{ School Type } \\
\hline Academies & $27 \%$ & $19 \%$ & $41 \%$ & $9 \%$ & $4 \%$ & 135 & $76 \%$ \\
\hline Not Academies & $39 \%$ & $29 \%$ & $24 \%$ & $3 \%$ & $5 \%$ & 43 & $24 \%$ \\
\hline Total & $30 \%$ & $21 \%$ & $37 \%$ & $8 \%$ & $5 \%$ & 178 & $100 \%$ \\
\hline \multicolumn{8}{|l|}{ School Enrolment } \\
\hline Less Than 700 & $35 \%$ & $24 \%$ & $35 \%$ & $6 \%$ & $0 \%$ & 21 & $12 \%$ \\
\hline From 701 To 1,000 & $25 \%$ & $18 \%$ & $49 \%$ & $6 \%$ & $1 \%$ & 54 & $30 \%$ \\
\hline More Than 1,000 & $31 \%$ & $22 \%$ & $30 \%$ & $9 \%$ & $7 \%$ & 103 & $58 \%$ \\
\hline Total & $30 \%$ & $21 \%$ & $37 \%$ & $8 \%$ & $5 \%$ & 178 & $100 \%$ \\
\hline
\end{tabular}

${ }^{1}$ For each pair of variables, a Chi-2 test was implemented. However, as these calculations were estimated using a post-stratification procedure (weights), the independence of the variables was assessed using the Pearson Chi-2 instead of the ordinary Chi-2 statistics (as the latter is less accurate measure when weights are applied). The details data of p-values and uncorrected Chi-2 statistics are presented as part of the supplementary material. *Significant at 0.05 level /** Significant at 0.01 level / *** Significant at 0.001 level. The number of observations may vary across variables and years due to two reasons: missing data for specific variables or differences in the number of respondents answering "Don't Know/ NA" (these options were excluded from the analysis). 


\begin{tabular}{|c|c|c|c|c|c|c|c|}
\hline \multicolumn{8}{|l|}{ Gender Of Entry * } \\
\hline Boys & $19 \%$ & $0 \%$ & $81 \%$ & $0 \%$ & $0 \%$ & 3 & $2 \%$ \\
\hline Girls & $38 \%$ & $0 \%$ & $17 \%$ & $36 \%$ & $10 \%$ & 8 & $5 \%$ \\
\hline Mixed & $30 \%$ & $23 \%$ & $37 \%$ & $6 \%$ & $4 \%$ & 166 & $93 \%$ \\
\hline Total & $30 \%$ & $21 \%$ & $37 \%$ & $8 \%$ & $5 \%$ & 178 & $100 \%$ \\
\hline \multicolumn{8}{|l|}{ Sixth Form School } \\
\hline No Sixth Form & $33 \%$ & $19 \%$ & $42 \%$ & $6 \%$ & $0 \%$ & 65 & $36 \%$ \\
\hline Has A Sixth Form & $28 \%$ & $23 \%$ & $34 \%$ & $9 \%$ & $7 \%$ & 113 & $64 \%$ \\
\hline Total & $30 \%$ & $21 \%$ & $37 \%$ & $8 \%$ & $5 \%$ & 178 & $100 \%$ \\
\hline \multicolumn{8}{|l|}{ Ofsted Rating ** } \\
\hline Outstanding & $38 \%$ & $15 \%$ & $25 \%$ & $7 \%$ & $16 \%$ & 35 & $20 \%$ \\
\hline Good & $27 \%$ & $28 \%$ & $33 \%$ & $9 \%$ & $4 \%$ & 108 & $61 \%$ \\
\hline Requires Improvement/Inadequate & $35 \%$ & $7 \%$ & $57 \%$ & $1 \%$ & $0 \%$ & 35 & $20 \%$ \\
\hline Total & $30 \%$ & $21 \%$ & $37 \%$ & $8 \%$ & $5 \%$ & 178 & $100 \%$ \\
\hline \multicolumn{8}{|l|}{ EAL * } \\
\hline Less Than $10 \%$ & $26 \%$ & $23 \%$ & $40 \%$ & $5 \%$ & $6 \%$ & 107 & $60 \%$ \\
\hline From $10 \%$ To $25 \%$ & $41 \%$ & $21 \%$ & $38 \%$ & $0 \%$ & $0 \%$ & 41 & $23 \%$ \\
\hline More Than 25\% & $34 \%$ & $14 \%$ & $22 \%$ & $27 \%$ & $3 \%$ & 30 & $17 \%$ \\
\hline Total & $30 \%$ & $21 \%$ & $37 \%$ & $8 \%$ & $5 \%$ & 178 & $100 \%$ \\
\hline \multicolumn{8}{|l|}{ Ever6 FSM *** } \\
\hline Low $(<=20.7 \%)$ & $40 \%$ & $23 \%$ & $26 \%$ & $4 \%$ & $8 \%$ & 62 & $35 \%$ \\
\hline Medium $(>20.7 \% \mid<35.4 \%)$ & $20 \%$ & $26 \%$ & $42 \%$ & $9 \%$ & $3 \%$ & 67 & $38 \%$ \\
\hline $\operatorname{High}(>=35.4 \%)$ & $29 \%$ & $13 \%$ & $46 \%$ & $11 \%$ & $2 \%$ & 48 & $27 \%$ \\
\hline Total & $30 \%$ & $21 \%$ & $37 \%$ & $8 \%$ & $5 \%$ & 178 & $100 \%$ \\
\hline \multicolumn{8}{|l|}{ Sen Students With Ehc Plan } \\
\hline Low & $26 \%$ & $23 \%$ & $37 \%$ & $9 \%$ & $5 \%$ & 54 & $30 \%$ \\
\hline Medium & $28 \%$ & $19 \%$ & $39 \%$ & $7 \%$ & $8 \%$ & 69 & $39 \%$ \\
\hline High & $36 \%$ & $23 \%$ & $33 \%$ & $7 \%$ & $0 \%$ & 55 & $31 \%$ \\
\hline Total & $30 \%$ & $21 \%$ & $37 \%$ & $8 \%$ & $5 \%$ & 178 & $100 \%$ \\
\hline \multicolumn{8}{|l|}{ Measure Of Attainment ** } \\
\hline Low & $21 \%$ & $17 \%$ & $51 \%$ & $11 \%$ & $0 \%$ & 70 & $41 \%$ \\
\hline Medium & $31 \%$ & $28 \%$ & $29 \%$ & $5 \%$ & $8 \%$ & 65 & $38 \%$ \\
\hline High & $51 \%$ & $19 \%$ & $19 \%$ & $5 \%$ & $7 \%$ & 37 & $22 \%$ \\
\hline Total & $30 \%$ & $22 \%$ & $37 \%$ & $8 \%$ & $4 \%$ & 172 & $100 \%$ \\
\hline
\end{tabular}

\begin{tabular}{|c|c|c|c|c|c|c|c|}
\hline & \multicolumn{7}{|c|}{ Current practices /English / Year 8} \\
\hline & 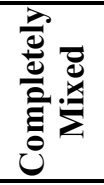 & 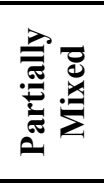 & $\frac{n}{\ddot{n}}$ & & $\frac{\bar{\Xi}}{\overline{0}}$ & & \\
\hline Region * & $\%$ & $\%$ & $\%$ & $\%$ & $\%$ & $\mathbf{N}$ & $\%$ \\
\hline
\end{tabular}




\begin{tabular}{|c|c|c|c|c|c|c|c|}
\hline North & $1 \%$ & $21 \%$ & $69 \%$ & $9 \%$ & $0 \%$ & 23 & $13 \%$ \\
\hline London & $54 \%$ & $12 \%$ & $23 \%$ & $11 \%$ & $0 \%$ & 26 & $15 \%$ \\
\hline Midlands (East \& West) & $22 \%$ & $17 \%$ & $41 \%$ & $15 \%$ & $5 \%$ & 74 & $42 \%$ \\
\hline South & $26 \%$ & $24 \%$ & $41 \%$ & $3 \%$ & $7 \%$ & 54 & $30 \%$ \\
\hline Total & $24 \%$ & $19 \%$ & $43 \%$ & $10 \%$ & $4 \%$ & 178 & $100 \%$ \\
\hline \multicolumn{8}{|l|}{ Urban - Rural * } \\
\hline Predominantly Rural & $21 \%$ & $10 \%$ & $54 \%$ & $7 \%$ & $7 \%$ & 11 & $6 \%$ \\
\hline Predominantly Urban & $23 \%$ & $19 \%$ & $38 \%$ & $18 \%$ & $1 \%$ & 71 & $40 \%$ \\
\hline Mixed & $24 \%$ & $20 \%$ & $45 \%$ & $5 \%$ & $6 \%$ & 95 & $54 \%$ \\
\hline Total & $24 \%$ & $19 \%$ & $43 \%$ & $10 \%$ & $4 \%$ & 178 & $100 \%$ \\
\hline \multicolumn{8}{|l|}{ School Type } \\
\hline Academies & $23 \%$ & $16 \%$ & $46 \%$ & $11 \%$ & $4 \%$ & 135 & $76 \%$ \\
\hline Not Academies & $27 \%$ & $29 \%$ & $33 \%$ & $7 \%$ & $5 \%$ & 43 & $24 \%$ \\
\hline Total & $24 \%$ & $19 \%$ & $43 \%$ & $10 \%$ & $4 \%$ & 178 & $100 \%$ \\
\hline \multicolumn{8}{|l|}{ School Enrolment } \\
\hline Less Than 700 & $29 \%$ & $10 \%$ & $53 \%$ & $8 \%$ & $0 \%$ & 21 & $12 \%$ \\
\hline From 701 To 1,000 & $21 \%$ & $14 \%$ & $56 \%$ & $9 \%$ & $0 \%$ & 54 & $30 \%$ \\
\hline More Than 1,000 & $238200 \%$ & $23 \%$ & $34 \%$ & $11 \%$ & $7 \%$ & 103 & $58 \%$ \\
\hline Total & $24 \%$ & $19 \%$ & $43 \%$ & $10 \%$ & $4 \%$ & 178 & $100 \%$ \\
\hline \multicolumn{8}{|l|}{ Gender Of Entry } \\
\hline Boys & $19 \%$ & $0 \%$ & $81 \%$ & $0 \%$ & $0 \%$ & 3 & $2 \%$ \\
\hline Girls & $31 \%$ & $0 \%$ & $23 \%$ & $36 \%$ & $10 \%$ & 8 & $5 \%$ \\
\hline Mixed & $23 \%$ & $20 \%$ & $43 \%$ & $9 \%$ & $4 \%$ & 166 & $93 \%$ \\
\hline Total & $24 \%$ & $19 \%$ & $43 \%$ & $10 \%$ & $4 \%$ & 178 & $100 \%$ \\
\hline \multicolumn{8}{|l|}{ Sixth Form School } \\
\hline No Sixth Form & $28 \%$ & $12 \%$ & $49 \%$ & $11 \%$ & $0 \%$ & 65 & $36 \%$ \\
\hline Has A Sixth Form & $21 \%$ & $23 \%$ & $40 \%$ & $9 \%$ & $7 \%$ & 113 & $64 \%$ \\
\hline Total & $24 \%$ & $19 \%$ & $43 \%$ & $10 \%$ & $4 \%$ & 178 & $100 \%$ \\
\hline \multicolumn{8}{|l|}{ Ofsted Rating $* * *$} \\
\hline Outstanding & $29 \%$ & $13 \%$ & $36 \%$ & $8 \%$ & $15 \%$ & 35 & $20 \%$ \\
\hline Good & $24 \%$ & $28 \%$ & $35 \%$ & $12 \%$ & $2 \%$ & 108 & $61 \%$ \\
\hline Requires Improvement/Inadequate & $21 \%$ & $3 \%$ & $72 \%$ & $5 \%$ & $0 \%$ & 35 & $20 \%$ \\
\hline Total & $24 \%$ & $19 \%$ & $43 \%$ & $10 \%$ & $4 \%$ & 178 & $100 \%$ \\
\hline \multicolumn{8}{|l|}{ EAL ** } \\
\hline Less Than $10 \%$ & $18 \%$ & $18 \%$ & $51 \%$ & $7 \%$ & $6 \%$ & 107 & $60 \%$ \\
\hline From $10 \%$ To $25 \%$ & $36 \%$ & $26 \%$ & $38 \%$ & $0 \%$ & $0 \%$ & 41 & $23 \%$ \\
\hline More Than 25\% & $31 \%$ & $14 \%$ & $18 \%$ & $34 \%$ & $3 \%$ & 30 & $17 \%$ \\
\hline Total & $24 \%$ & $19 \%$ & $43 \%$ & $10 \%$ & $4 \%$ & 178 & $100 \%$ \\
\hline \multicolumn{8}{|l|}{ Ever6 FSM *** } \\
\hline Low $(<=20.7 \%)$ & $32 \%$ & $17 \%$ & $36 \%$ & $8 \%$ & $8 \%$ & 62 & $35 \%$ \\
\hline Medium $(>20.7 \% \mid<35.4 \%)$ & $18 \%$ & $24 \%$ & $45 \%$ & $11 \%$ & $2 \%$ & 67 & $38 \%$ \\
\hline
\end{tabular}




\begin{tabular}{|l|c|c|c|c|c|c|c|} 
High $(>=35.4 \%)$ & $21 \%$ & $15 \%$ & $50 \%$ & $13 \%$ & $2 \%$ & 48 & $27 \%$ \\
\hline Total & $24 \%$ & $19 \%$ & $43 \%$ & $10 \%$ & $4 \%$ & 178 & $100 \%$ \\
\hline Sen Students With Ehc Plan & & & & & & & \\
\hline Low & $15 \%$ & $19 \%$ & $48 \%$ & $12 \%$ & $5 \%$ & 54 & $30 \%$ \\
\hline Medium & $27 \%$ & $18 \%$ & $41 \%$ & $7 \%$ & $7 \%$ & 69 & $39 \%$ \\
\hline High & $28 \%$ & $20 \%$ & $40 \%$ & $12 \%$ & $0 \%$ & 55 & $31 \%$ \\
\hline Total & $24 \%$ & $19 \%$ & $43 \%$ & $10 \%$ & $4 \%$ & 178 & $100 \%$ \\
\hline Measure Of Attainment * & & & & & & & \\
\hline Low & $17 \%$ & $18 \%$ & $55 \%$ & $10 \%$ & $0 \%$ & 70 & $41 \%$ \\
\hline Medium & $25 \%$ & $21 \%$ & $35 \%$ & $11 \%$ & $8 \%$ & 65 & $38 \%$ \\
\hline High & $39 \%$ & $19 \%$ & $27 \%$ & $7 \%$ & $8 \%$ & 37 & $22 \%$ \\
\hline Total & $24 \%$ & $19 \%$ & $43 \%$ & $10 \%$ & $4 \%$ & 172 & $100 \%$ \\
\hline
\end{tabular}

\begin{tabular}{|c|c|c|c|c|c|c|c|}
\hline \multirow[b]{3}{*}{ Region * } & \multicolumn{7}{|c|}{ Current practices /English / Year 9} \\
\hline & \multirow{2}{*}{$\frac{\%}{\%}$} & \multirow{2}{*}{ 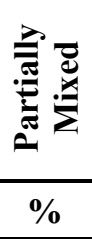 } & \multirow{2}{*}{$\begin{array}{c}\frac{n}{0} \\
\dot{m} \\
\%\end{array}$} & \multirow{2}{*}{ 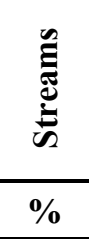 } & \multirow{2}{*}{$\begin{array}{c}\grave{\bar{\Xi}} \\
\%\end{array}$} & \multicolumn{2}{|c|}{ 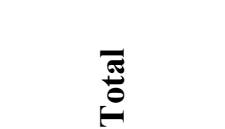 } \\
\hline & & & & & & $\mathbf{N}$ & $\%$ \\
\hline North & $1 \%$ & $19 \%$ & $75 \%$ & $5 \%$ & $0 \%$ & 22 & $13 \%$ \\
\hline London & $32 \%$ & $24 \%$ & $34 \%$ & $11 \%$ & $0 \%$ & 26 & $15 \%$ \\
\hline Midlands (East \& West) & $15 \%$ & $25 \%$ & $45 \%$ & $10 \%$ & $5 \%$ & 73 & $42 \%$ \\
\hline South & $22 \%$ & $33 \%$ & $41 \%$ & $4 \%$ & $0 \%$ & 53 & $30 \%$ \\
\hline Total & $18 \%$ & $26 \%$ & $47 \%$ & $8 \%$ & $2 \%$ & 174 & $100 \%$ \\
\hline \multicolumn{8}{|l|}{ Urban - Rural ** } \\
\hline Predominantly Rural & $5 \%$ & $36 \%$ & $54 \%$ & $0 \%$ & $5 \%$ & 11 & $6 \%$ \\
\hline Predominantly Urban & $12 \%$ & $26 \%$ & $46 \%$ & $15 \%$ & $1 \%$ & 70 & $40 \%$ \\
\hline Mixed & $23 \%$ & $25 \%$ & $47 \%$ & $3 \%$ & $2 \%$ & 93 & $54 \%$ \\
\hline Total & $18 \%$ & $26 \%$ & $47 \%$ & $8 \%$ & $2 \%$ & 174 & $100 \%$ \\
\hline \multicolumn{8}{|l|}{ School Type * } \\
\hline Academies & $18 \%$ & $22 \%$ & $49 \%$ & $9 \%$ & $2 \%$ & 132 & $76 \%$ \\
\hline Not Academies & $18 \%$ & $37 \%$ & $39 \%$ & $4 \%$ & $2 \%$ & 42 & $24 \%$ \\
\hline Total & $18 \%$ & $26 \%$ & $47 \%$ & $8 \%$ & $2 \%$ & 174 & $100 \%$ \\
\hline \multicolumn{8}{|l|}{ School Enrolment } \\
\hline Less Than 700 & $12 \%$ & $21 \%$ & $55 \%$ & $8 \%$ & $3 \%$ & 20 & $12 \%$ \\
\hline From 701 To 1,000 & $11 \%$ & $22 \%$ & $58 \%$ & $9 \%$ & $0 \%$ & 53 & $30 \%$ \\
\hline More Than 1,000 & $22 \%$ & $29 \%$ & $39 \%$ & $7 \%$ & $3 \%$ & 101 & $58 \%$ \\
\hline Total & $18 \%$ & $26 \%$ & $47 \%$ & $8 \%$ & $2 \%$ & 174 & $100 \%$ \\
\hline \multicolumn{8}{|l|}{ Gender Of Entry * } \\
\hline Boys & $19 \%$ & $0 \%$ & $81 \%$ & $0 \%$ & $0 \%$ & 3 & $2 \%$ \\
\hline Girls & $31 \%$ & $0 \%$ & $34 \%$ & $25 \%$ & $10 \%$ & 8 & $5 \%$ \\
\hline
\end{tabular}




\begin{tabular}{|c|c|c|c|c|c|c|c|}
\hline Mixed & $17 \%$ & $28 \%$ & $47 \%$ & $7 \%$ & $2 \%$ & 162 & $93 \%$ \\
\hline Total & $18 \%$ & $26 \%$ & $47 \%$ & $8 \%$ & $2 \%$ & 174 & $100 \%$ \\
\hline \multicolumn{8}{|l|}{ Sixth Form School } \\
\hline No Sixth Form & $15 \%$ & $21 \%$ & $51 \%$ & $11 \%$ & $1 \%$ & 63 & $36 \%$ \\
\hline Has A Sixth Form & $19 \%$ & $29 \%$ & $44 \%$ & $5 \%$ & $3 \%$ & 111 & $64 \%$ \\
\hline Total & $18 \%$ & $26 \%$ & $47 \%$ & $8 \%$ & $2 \%$ & 174 & $100 \%$ \\
\hline \multicolumn{8}{|l|}{ Ofsted Rating ** } \\
\hline Outstanding & $28 \%$ & $16 \%$ & $41 \%$ & $7 \%$ & $8 \%$ & 34 & $20 \%$ \\
\hline Good & $15 \%$ & $36 \%$ & $41 \%$ & $7 \%$ & $1 \%$ & 105 & $61 \%$ \\
\hline Requires Improvement/Inadequate & $17 \%$ & $7 \%$ & $72 \%$ & $5 \%$ & $0 \%$ & 34 & $20 \%$ \\
\hline Total & $18 \%$ & $26 \%$ & $47 \%$ & $8 \%$ & $2 \%$ & 174 & $100 \%$ \\
\hline \multicolumn{8}{|l|}{ EAL * } \\
\hline Less Than $10 \%$ & $13 \%$ & $28 \%$ & $52 \%$ & $4 \%$ & $2 \%$ & 107 & $60 \%$ \\
\hline From $10 \%$ To $25 \%$ & $30 \%$ & $27 \%$ & $40 \%$ & $3 \%$ & $0 \%$ & 41 & $23 \%$ \\
\hline More Than $25 \%$ & $20 \%$ & $19 \%$ & $34 \%$ & $24 \%$ & $3 \%$ & 30 & $17 \%$ \\
\hline Total & $18 \%$ & $26 \%$ & $47 \%$ & $8 \%$ & $2 \%$ & 178 & $100 \%$ \\
\hline \multicolumn{8}{|l|}{ Ever6 FSM *** } \\
\hline Low $(<=20.7 \%)$ & $23 \%$ & $31 \%$ & $37 \%$ & $5 \%$ & $4 \%$ & 61 & $35 \%$ \\
\hline Medium $(>20.7 \% \mid<35.4 \%)$ & $12 \%$ & $30 \%$ & $49 \%$ & $10 \%$ & $0 \%$ & 66 & $38 \%$ \\
\hline $\operatorname{High}(>=35.4 \%)$ & $18 \%$ & $13 \%$ & $58 \%$ & $9 \%$ & $2 \%$ & 47 & $27 \%$ \\
\hline Total & $18 \%$ & $26 \%$ & $47 \%$ & $8 \%$ & $2 \%$ & 174 & $100 \%$ \\
\hline \multicolumn{8}{|l|}{ Sen Students With Ehc Plan } \\
\hline Low & $10 \%$ & $24 \%$ & $52 \%$ & $9 \%$ & $5 \%$ & 52 & $30 \%$ \\
\hline Medium & $24 \%$ & $26 \%$ & $45 \%$ & $5 \%$ & $0 \%$ & 68 & $39 \%$ \\
\hline High & $18 \%$ & $27 \%$ & $44 \%$ & $9 \%$ & $1 \%$ & 54 & $31 \%$ \\
\hline Total & $18 \%$ & $26 \%$ & $47 \%$ & $8 \%$ & $2 \%$ & 174 & $100 \%$ \\
\hline \multicolumn{8}{|l|}{ Measure Of Attainment * } \\
\hline Low & $12 \%$ & $23 \%$ & $59 \%$ & $6 \%$ & $0 \%$ & 68 & $41 \%$ \\
\hline Medium & $20 \%$ & $28 \%$ & $40 \%$ & $10 \%$ & $1 \%$ & 63 & $38 \%$ \\
\hline High & $26 \%$ & $30 \%$ & $32 \%$ & $5 \%$ & $7 \%$ & 37 & $22 \%$ \\
\hline Total & $18 \%$ & $26 \%$ & $46 \%$ & $8 \%$ & $2 \%$ & 168 & $100 \%$ \\
\hline
\end{tabular}

\begin{tabular}{|c|c|c|c|c|c|c|c|}
\hline & \multicolumn{7}{|c|}{ Current practices /English / Year 10} \\
\hline & 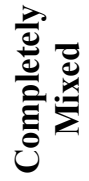 & 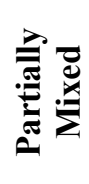 & $\frac{n}{\tilde{n}}$ & 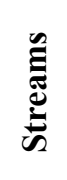 & 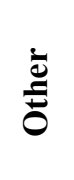 & & \\
\hline Region ** & $\%$ & $\%$ & $\%$ & $\%$ & $\%$ & $\mathbf{N}$ & $\%$ \\
\hline North & $0 \%$ & $21 \%$ & $79 \%$ & $0 \%$ & $0 \%$ & 22 & $13 \%$ \\
\hline London & $25 \%$ & $25 \%$ & $43 \%$ & $4 \%$ & $4 \%$ & 26 & $15 \%$ \\
\hline Midlands (East \& West) & $12 \%$ & $16 \%$ & $57 \%$ & $7 \%$ & $8 \%$ & 73 & $42 \%$ \\
\hline
\end{tabular}




\begin{tabular}{|c|c|c|c|c|c|c|c|}
\hline South & $14 \%$ & $41 \%$ & $39 \%$ & $6 \%$ & $0 \%$ & 53 & $30 \%$ \\
\hline Total & $12 \%$ & $25 \%$ & $53 \%$ & $6 \%$ & $4 \%$ & 174 & $100 \%$ \\
\hline \multicolumn{8}{|l|}{ Urban - Rural ** } \\
\hline Predominantly Rural & $0 \%$ & $18 \%$ & $55 \%$ & $7 \%$ & $20 \%$ & 11 & $6 \%$ \\
\hline Predominantly Urban & $8 \%$ & $27 \%$ & $53 \%$ & $10 \%$ & $2 \%$ & 70 & $40 \%$ \\
\hline Mixed & $16 \%$ & $24 \%$ & $53 \%$ & $3 \%$ & $3 \%$ & 93 & $54 \%$ \\
\hline Total & $12 \%$ & $25 \%$ & $53 \%$ & $6 \%$ & $4 \%$ & 174 & $100 \%$ \\
\hline \multicolumn{8}{|l|}{ School Type } \\
\hline Academies & $12 \%$ & $22 \%$ & $56 \%$ & $6 \%$ & $4 \%$ & 132 & $76 \%$ \\
\hline Not Academies & $12 \%$ & $33 \%$ & $45 \%$ & $5 \%$ & $5 \%$ & 42 & $24 \%$ \\
\hline Total & $12 \%$ & $25 \%$ & $53 \%$ & $6 \%$ & $4 \%$ & 174 & $100 \%$ \\
\hline \multicolumn{8}{|l|}{ School Enrolment } \\
\hline Less Than 700 & $6 \%$ & $18 \%$ & $59 \%$ & $8 \%$ & $9 \%$ & 20 & $12 \%$ \\
\hline From 701 To 1,000 & $9 \%$ & $22 \%$ & $62 \%$ & $6 \%$ & $1 \%$ & 53 & $30 \%$ \\
\hline More Than 1,000 & $15 \%$ & $27 \%$ & $48 \%$ & $6 \%$ & $4 \%$ & 101 & $58 \%$ \\
\hline Total & $12 \%$ & $25 \%$ & $53 \%$ & $6 \%$ & $4 \%$ & 174 & $100 \%$ \\
\hline \multicolumn{8}{|l|}{ Gender Of Entry } \\
\hline Boys & $19 \%$ & $0 \%$ & $81 \%$ & $0 \%$ & $0 \%$ & 3 & $2 \%$ \\
\hline Girls & $23 \%$ & $0 \%$ & $67 \%$ & $0 \%$ & $10 \%$ & 8 & $5 \%$ \\
\hline Mixed & $11 \%$ & $27 \%$ & $52 \%$ & $6 \%$ & $4 \%$ & 162 & $93 \%$ \\
\hline Total & $12 \%$ & $25 \%$ & $53 \%$ & $6 \%$ & $4 \%$ & 174 & $100 \%$ \\
\hline \multicolumn{8}{|l|}{ Sixth Form School ** } \\
\hline No Sixth Form & $6 \%$ & $24 \%$ & $56 \%$ & $11 \%$ & $4 \%$ & 63 & $36 \%$ \\
\hline Has A Sixth Form & $15 \%$ & $25 \%$ & $52 \%$ & $3 \%$ & $4 \%$ & 111 & $64 \%$ \\
\hline Total & $12 \%$ & $25 \%$ & $53 \%$ & $6 \%$ & $4 \%$ & 174 & $100 \%$ \\
\hline \multicolumn{8}{|l|}{ Ofsted Rating ** } \\
\hline Outstanding & $18 \%$ & $22 \%$ & $49 \%$ & $2 \%$ & $8 \%$ & 34 & $20 \%$ \\
\hline Good & $10 \%$ & $35 \%$ & $44 \%$ & $8 \%$ & $4 \%$ & 105 & $61 \%$ \\
\hline Requires Improvement/Inadequate & $16 \%$ & $6 \%$ & $74 \%$ & $5 \%$ & $0 \%$ & 34 & $20 \%$ \\
\hline Total & $12 \%$ & $25 \%$ & $53 \%$ & $6 \%$ & $4 \%$ & 174 & $100 \%$ \\
\hline \multicolumn{8}{|l|}{ EAL } \\
\hline Less Than $10 \%$ & $9 \%$ & $26 \%$ & $58 \%$ & $4 \%$ & $4 \%$ & 104 & $60 \%$ \\
\hline From $10 \%$ To $25 \%$ & $23 \%$ & $25 \%$ & $40 \%$ & $6 \%$ & $6 \%$ & 40 & $23 \%$ \\
\hline More Than 25\% & $12 \%$ & $20 \%$ & $52 \%$ & $13 \%$ & $3 \%$ & 30 & $17 \%$ \\
\hline Total & $12 \%$ & $25 \%$ & $53 \%$ & $6 \%$ & $4 \%$ & 174 & $100 \%$ \\
\hline \multicolumn{8}{|l|}{ Ever6 FSM } \\
\hline Low $(<=20.7 \%)$ & $14 \%$ & $27 \%$ & $45 \%$ & $8 \%$ & $6 \%$ & 61 & $35 \%$ \\
\hline Medium $(>20.7 \% \mid<35.4 \%)$ & $10 \%$ & $30 \%$ & $55 \%$ & $5 \%$ & $1 \%$ & 66 & $38 \%$ \\
\hline $\operatorname{High}(>=35.4 \%)$ & $13 \%$ & $14 \%$ & $64 \%$ & $4 \%$ & $5 \%$ & 47 & $27 \%$ \\
\hline Total & $12 \%$ & $25 \%$ & $53 \%$ & $6 \%$ & $4 \%$ & 174 & $100 \%$ \\
\hline Sen Students With Ehc Plan ** & & & & & & & \\
\hline
\end{tabular}




\begin{tabular}{|l|c|c|c|c|c|c|c|} 
Low & $5 \%$ & $22 \%$ & $65 \%$ & $1 \%$ & $7 \%$ & 52 & $30 \%$ \\
\hline Medium & $17 \%$ & $29 \%$ & $46 \%$ & $8 \%$ & $0 \%$ & 68 & $39 \%$ \\
\hline High & $13 \%$ & $22 \%$ & $50 \%$ & $9 \%$ & $6 \%$ & 54 & $31 \%$ \\
\hline Total & $12 \%$ & $25 \%$ & $53 \%$ & $6 \%$ & $4 \%$ & 174 & $100 \%$ \\
\hline Measure Of Attainment * & & & & & & & \\
\hline Low & $12 \%$ & $19 \%$ & $64 \%$ & $3 \%$ & $1 \%$ & 68 & $41 \%$ \\
\hline Medium & $12 \%$ & $30 \%$ & $44 \%$ & $10 \%$ & $3 \%$ & 63 & $38 \%$ \\
\hline High & $18 \%$ & $27 \%$ & $47 \%$ & $2 \%$ & $6 \%$ & 37 & $22 \%$ \\
\hline Total & $12 \%$ & $25 \%$ & $54 \%$ & $6 \%$ & $3 \%$ & 168 & $100 \%$ \\
\hline
\end{tabular}

\begin{tabular}{|c|c|c|c|c|c|c|c|}
\hline & \multicolumn{7}{|c|}{ Current practices /English / Year 11} \\
\hline & \multirow{2}{*}{ 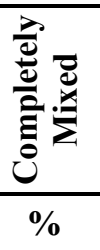 } & \multirow{2}{*}{ 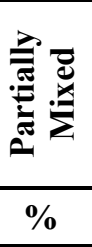 } & \multirow{2}{*}{$\begin{array}{l}0 \\
\stackrel{0}{0} \\
\%\end{array}$} & \multirow{2}{*}{ 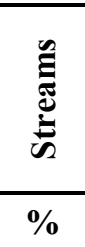 } & \multirow{2}{*}{$\begin{array}{l}\dot{\bar{\Xi}} \\
\overline{0}\end{array}$} & \multicolumn{2}{|c|}{$\stackrel{\bar{\sigma}}{\theta}$} \\
\hline Region ** & & & & & & $\mathbf{N}$ & $\%$ \\
\hline North & $0 \%$ & $21 \%$ & $79 \%$ & $0 \%$ & $0 \%$ & 22 & $13 \%$ \\
\hline London & $17 \%$ & $26 \%$ & $55 \%$ & $0 \%$ & $3 \%$ & 26 & $15 \%$ \\
\hline Midlands (East \& West) & $8 \%$ & $28 \%$ & $51 \%$ & $6 \%$ & $7 \%$ & 73 & $42 \%$ \\
\hline South & $16 \%$ & $36 \%$ & $42 \%$ & $7 \%$ & $0 \%$ & 53 & $30 \%$ \\
\hline Total & $10 \%$ & $28 \%$ & $54 \%$ & $5 \%$ & $3 \%$ & 174 & $100 \%$ \\
\hline \multicolumn{8}{|l|}{ Urban - Rural *** } \\
\hline Predominantly Rural & $7 \%$ & $18 \%$ & $55 \%$ & $0 \%$ & $20 \%$ & 11 & $6 \%$ \\
\hline Predominantly Urban & $5 \%$ & $23 \%$ & $61 \%$ & $10 \%$ & $2 \%$ & 70 & $40 \%$ \\
\hline Mixed & $13 \%$ & $33 \%$ & $49 \%$ & $2 \%$ & $2 \%$ & 93 & $54 \%$ \\
\hline Total & $10 \%$ & $28 \%$ & $54 \%$ & $5 \%$ & $3 \%$ & 174 & $100 \%$ \\
\hline \multicolumn{8}{|l|}{ School Type } \\
\hline Academies & $10 \%$ & $27 \%$ & $56 \%$ & $5 \%$ & $3 \%$ & 132 & $76 \%$ \\
\hline Not Academies & $9 \%$ & $33 \%$ & $48 \%$ & $5 \%$ & $5 \%$ & 42 & $24 \%$ \\
\hline Total & $10 \%$ & $28 \%$ & $54 \%$ & $5 \%$ & $3 \%$ & 174 & $100 \%$ \\
\hline \multicolumn{8}{|l|}{ School Enrolment } \\
\hline Less Than 700 & $14 \%$ & $10 \%$ & $62 \%$ & $6 \%$ & $9 \%$ & 20 & $12 \%$ \\
\hline From 701 To 1,000 & $8 \%$ & $26 \%$ & $61 \%$ & $3 \%$ & $1 \%$ & 53 & $30 \%$ \\
\hline More Than 1,000 & $10 \%$ & $32 \%$ & $49 \%$ & $6 \%$ & $4 \%$ & 101 & $58 \%$ \\
\hline Total & $10 \%$ & $28 \%$ & $54 \%$ & $5 \%$ & $3 \%$ & 174 & $100 \%$ \\
\hline \multicolumn{8}{|l|}{ Gender Of Entry } \\
\hline Boys & $19 \%$ & $0 \%$ & $81 \%$ & $0 \%$ & $0 \%$ & 3 & $2 \%$ \\
\hline Girls & $23 \%$ & $0 \%$ & $67 \%$ & $0 \%$ & $10 \%$ & 8 & $5 \%$ \\
\hline Mixed & $9 \%$ & $30 \%$ & $53 \%$ & $5 \%$ & $3 \%$ & 166 & $93 \%$ \\
\hline Total & $10 \%$ & $28 \%$ & $54 \%$ & $5 \%$ & $3 \%$ & 178 & $100 \%$ \\
\hline Sixth Form School * & & & & & & & \\
\hline
\end{tabular}




\begin{tabular}{|l|c|c|c|c|c|c|c|} 
No Sixth Form & $8 \%$ & $27 \%$ & $53 \%$ & $8 \%$ & $4 \%$ & 63 & $36 \%$ \\
\hline Has A Sixth Form & $11 \%$ & $28 \%$ & $54 \%$ & $3 \%$ & $3 \%$ & 111 & $64 \%$ \\
\hline Total & $10 \%$ & $28 \%$ & $54 \%$ & $5 \%$ & $3 \%$ & 174 & $100 \%$ \\
\hline Ofsted Rating ** & & & & & & & \\
\hline Outstanding & $14 \%$ & $22 \%$ & $53 \%$ & $3 \%$ & $8 \%$ & 34 & $20 \%$ \\
\hline Good & $9 \%$ & $33 \%$ & $49 \%$ & $5 \%$ & $3 \%$ & 105 & $61 \%$ \\
\hline Requires Improvement/Inadequate & $9 \%$ & $24 \%$ & $63 \%$ & $5 \%$ & $0 \%$ & 34 & $20 \%$ \\
\hline Total & $10 \%$ & $28 \%$ & $54 \%$ & $5 \%$ & $3 \%$ & 174 & $100 \%$ \\
\hline EAL & & & & & & & \\
\hline Less Than 10\% & $10 \%$ & $29 \%$ & $56 \%$ & $3 \%$ & $3 \%$ & 104 & $60 \%$ \\
\hline From 10\% To 25\% & $9 \%$ & $33 \%$ & $47 \%$ & $5 \%$ & $6 \%$ & 40 & $23 \%$ \\
\hline More Than 25\% & $8 \%$ & $20 \%$ & $56 \%$ & $13 \%$ & $3 \%$ & 30 & $17 \%$ \\
\hline Total & $10 \%$ & $28 \%$ & $54 \%$ & $5 \%$ & $3 \%$ & 174 & $100 \%$ \\
\hline Ever6 FSM * & & & & & & & \\
\hline Low (<=20.7\%) & $15 \%$ & $32 \%$ & $41 \%$ & $6 \%$ & $6 \%$ & 61 & $35 \%$ \\
\hline Medium (>20.7\% $<35.4 \%)$ & $9 \%$ & $27 \%$ & $59 \%$ & $5 \%$ & $1 \%$ & 66 & $38 \%$ \\
\hline High (>=35.4\%) & $3 \%$ & $24 \%$ & $66 \%$ & $4 \%$ & $3 \%$ & 47 & $27 \%$ \\
\hline Total & $10 \%$ & $28 \%$ & $54 \%$ & $5 \%$ & $3 \%$ & 174 & $100 \%$ \\
\hline Sen Students With Ehc Plan ** & & & & & & & \\
\hline Low & $5 \%$ & $26 \%$ & $61 \%$ & $2 \%$ & $7 \%$ & 52 & $30 \%$ \\
\hline Medium & $18 \%$ & $29 \%$ & $47 \%$ & $6 \%$ & $0 \%$ & 68 & $39 \%$ \\
\hline High & $4 \%$ & $29 \%$ & $56 \%$ & $7 \%$ & $5 \%$ & 54 & $31 \%$ \\
\hline Total & $10 \%$ & $28 \%$ & $54 \%$ & $5 \%$ & $3 \%$ & 174 & $100 \%$ \\
\hline Measure Of Attainment ** & & & & & & & \\
\hline Low & $10 \%$ & $32 \%$ & $49 \%$ & $7 \%$ & $2 \%$ & 64 & $38 \%$ \\
\hline Medium & $10 \%$ & $28 \%$ & $55 \%$ & $5 \%$ & $2 \%$ & 168 & $100 \%$ \\
\hline High & & $28 \%$ & $61 \%$ & $3 \%$ & $0 \%$ & 68 & $40 \%$ \\
\hline Total & & & & & & \\
\hline
\end{tabular}

Stratums for weight adjustment (Expressed in percentages / $\mathbf{n = 2 , 7 6 2 )}$

\begin{tabular}{|l|r|r|r|r|r|r|r|r|r|}
\cline { 2 - 12 } \multicolumn{1}{c|}{} & \multicolumn{9}{c|}{ Enrolment } \\
\hline & \multicolumn{3}{c|}{ Less than 700 } & \multicolumn{3}{c|}{701 to 1000 } & \multicolumn{3}{c|}{ More than 1000 } \\
\hline \multicolumn{1}{c|}{ Ofsted Rating } & Out. & Good & Ina. & Out. & Good & Ina. & Out. & Good & Ina. \\
\hline Academies-converter & 1.1 & 6.7 & 1.9 & 3.7 & 9.9 & 2.2 & 8.3 & 11.1 & 1.8 \\
\hline Academies sponsor-led & 0.3 & 4.5 & 3.4 & 1.0 & 3.5 & 2.0 & 1.0 & 2.3 & 1.1 \\
\hline CTC & 0.0 & 0.0 & 0.0 & 0.0 & 0.0 & 0.0 & 0.1 & 0.0 & 0.0 \\
\hline Community School & 0.3 & 3.7 & 1.5 & 0.4 & 3.3 & 1.6 & 1.2 & 2.6 & 0.7 \\
\hline Foundation School & 0.1 & 1.7 & 0.7 & 0.4 & 1.1 & 0.6 & 0.9 & 1.8 & 0.7 \\
\hline
\end{tabular}




\begin{tabular}{|l|r|r|r|r|r|r|r|r|r|}
\hline Free school & 0.1 & 0.1 & 0.1 & 0.0 & 0.0 & 0.0 & 0.5 & 2.1 & 0.7 \\
\hline Voluntary Aided & 0.9 & 2.1 & 0.6 & 0.6 & 1.2 & 0.3 & 0.0 & 0.3 & 0.1 \\
\hline Voluntary Controlled & 0.0 & 0.3 & 0.1 & 0.0 & 0.1 & 0.1 & 0.1 & 0.4 & 0.0 \\
\hline
\end{tabular}

Note: The Ofsted rating is expressed in three categories: Outstanding (Out.), Good and Requires Improvement-

Inadequate (Ina). As the administrative records are not flawless, there is missing information about some

variables. In total, 2,762 schools presented full information in the variables used for estimating weights. This analysis assumes that missing data is at random but cannot discard some level of bias associated. 
Uncorrected Chi-2 statistics and Chi-2 Pearson correlation between Grouping practices and School-level descriptive variables by school year ( $<<0.05$ are highlighted)

\begin{tabular}{|c|c|c|c|c|c|c|c|c|c|c|}
\hline \multicolumn{11}{|c|}{ English } \\
\hline \multirow[t]{2}{*}{ Variable } & \multicolumn{2}{|c|}{$\hat{\check{J}}$} & \multicolumn{2}{|c|}{$\stackrel{\infty}{\stackrel{\infty}{\Xi}}$} & \multicolumn{2}{|c|}{$\stackrel{\vec{\Xi}}{\grave{\nu}}$} & \multicolumn{2}{|c|}{ 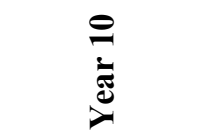 } & \multicolumn{2}{|c|}{$\underset{\bar{J}}{\bar{\Xi}}$} \\
\hline & Chi-2 & p & Chi-2 & $\mathbf{p}$ & Chi-2 & p & Chi-2 & p & Chi-2 & p \\
\hline Region & 23.863 & .002 & 29.765 & .023 & 22.596 & .044 & 29.538 & .001 & 21.692 & .005 \\
\hline Urban - Rural & 7.905 & .009 & 10.317 & .027 & 14.010 & .005 & 16.247 & .004 & 20.802 & .000 \\
\hline School Type & 7.418 & .107 & 5.233 & .058 & 4.601 & .024 & 2.393 & .086 & 1.218 & .175 \\
\hline School Enrolment & 8.837 & .284 & 13.022 & .596 & 8.595 & .324 & 6.515 & .192 & 8.112 & .073 \\
\hline Gender Of Entry & 15.852 & .038 & 11.452 & .092 & 11.881 & .038 & 6.782 & .451 & 8.235 & .222 \\
\hline Sixth Form School & 6.329 & .561 & 8.404 & .568 & 4.433 & .121 & 6.769 & .008 & 2.160 & .030 \\
\hline Ofsted Rating & 26.266 & .000 & 31.660 & .000 & 27.160 & .001 & 18.451 & .001 & 7.885 & .004 \\
\hline EAL & 26.778 & .012 & 36.280 & .001 & 21.327 & .025 & 9.669 & .203 & 6.546 & .184 \\
\hline Ever6 FSM & 14.461 & .000 & 10.222 & .000 & 13.448 & .000 & 8.772 & .096 & 11.533 & .010 \\
\hline $\begin{array}{l}\text { Sen Students With Ehe } \\
\text { Plan }\end{array}$ & 5.973 & .631 & 7.438 & .271 & 9.437 & .271 & 14.421 & .001 & 14.000 & .009 \\
\hline Attainment & 21.997 & .001 & 14.340 & .021 & 12.867 & .010 & 12.089 & .033 & 9.787 & .003 \\
\hline
\end{tabular}

\begin{tabular}{|c|c|c|c|c|c|c|c|c|c|c|}
\hline \multicolumn{11}{|c|}{ Mathematics } \\
\hline \multirow[t]{2}{*}{ Variable } & \multicolumn{2}{|c|}{$\hat{\check{E}}$} & \multicolumn{2}{|c|}{$\stackrel{\infty}{\grave{\Xi}}$} & \multicolumn{2}{|c|}{ 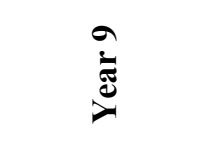 } & \multicolumn{2}{|c|}{ 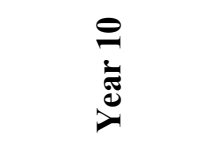 } & \multicolumn{2}{|c|}{ 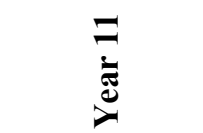 } \\
\hline & Chi-2 & $\mathbf{p}$ & Chi-2 & $\mathbf{P}$ & Chi-2 & $\mathbf{p}$ & Chi-2 & $\mathbf{p}$ & Chi-2 & p \\
\hline Region & 10.079 & .063 & 13.389 & .034 & 12.432 & .013 & 13.840 & .001 & 11.512 & .810 \\
\hline Urban - Rural & 10.036 & .156 & 13.925 & .009 & 6.417 & .268 & 12.820 & .003 & 8.857 & .655 \\
\hline School Type & 19.969 & .000 & 18.275 & .003 & 4.529 & .002 & 4.434 & .025 & 4.992 & .172 \\
\hline School Enrolment & 7.154 & .190 & 6.458 & .395 & 8.624 & .573 & 16.177 & .058 & 11.994 & .176 \\
\hline Gender Of Entry & 3.404 & .568 & 4.232 & .396 & 4.703 & .054 & 4.673 & .186 & 8.962 & .054 \\
\hline Sixth Form School & 0.726 & .027 & 1.105 & .002 & 3.285 & .108 & 6.615 & .037 & 2.806 & .553 \\
\hline Ofsted Rating & 11.037 & .093 & 5.873 & .506 & 9.279 & .007 & 9.796 & .004 & 14.431 & .184 \\
\hline EAL & 8.256 & .603 & 15.330 & .106 & 10.751 & .106 & 5.359 & .134 & 6.247 & .029 \\
\hline Ever6 FSM & 11.393 & .000 & 16.609 & .000 & 18.438 & .006 & 7.288 & .042 & 2.349 & .342 \\
\hline $\begin{array}{l}\text { Sen Students With Ehc } \\
\text { Plan }\end{array}$ & 8.805 & .010 & 12.762 & .024 & 3.760 & .041 & 9.642 & .000 & 4.097 & .309 \\
\hline Attainment & 16.750 & .029 & 12.383 & .061 & 4.909 & .010 & 8.413 & .043 & 8.263 & .427 \\
\hline
\end{tabular}




\begin{tabular}{|c|c|c|c|c|c|c|c|c|c|c|}
\hline \multicolumn{11}{|c|}{ Other Subjects } \\
\hline \multirow[t]{2}{*}{ Variable } & \multicolumn{2}{|c|}{$\stackrel{i}{\bar{\Xi}}$} & \multicolumn{2}{|c|}{ 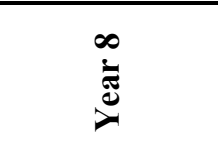 } & \multicolumn{2}{|c|}{$\stackrel{a}{\grave{\Xi}}$} & \multicolumn{2}{|c|}{ 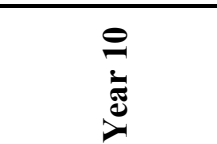 } & \multicolumn{2}{|c|}{$\begin{array}{l}= \\
\bar{\Xi} \\
\bar{\Xi}\end{array}$} \\
\hline & Chi-2 & p & Chi-2 & $\mathbf{p}$ & Chi-2 & $\mathbf{p}$ & Chi-2 & $\mathbf{p}$ & Chi-2 & $\mathbf{p}$ \\
\hline Region & 20.957 & .000 & 23.033 & .000 & 9.197 & .021 & 7.625 & .411 & 8.893 & .435 \\
\hline Urban - Rural & 10.919 & .002 & 10.698 & .000 & 5.672 & .000 & 9.286 & .004 & 9.513 & .000 \\
\hline School Type & 2.130 & .541 & 5.478 & .696 & 2.653 & .967 & 5.154 & .274 & 1.621 & .129 \\
\hline School Enrolment & 4.273 & .386 & 7.100 & .379 & 8.977 & .550 & 3.458 & .397 & 2.348 & .928 \\
\hline Gender Of Entry & 7.004 & .161 & 5.799 & .259 & 6.466 & .329 & 3.074 & .546 & 3.324 & .322 \\
\hline Sixth Form School & 1.606 & .116 & 0.676 & .535 & 0.090 & .038 & 0.010 & .309 & 0.637 & .486 \\
\hline Ofsted Rating & 3.598 & .736 & 4.309 & .384 & 2.463 & .408 & 3.331 & .125 & 4.790 & .020 \\
\hline EAL & 7.957 & .778 & 6.015 & .099 & 3.067 & .530 & 2.272 & .335 & 4.995 & .461 \\
\hline Ever6 FSM & 17.679 & .003 & 6.560 & .040 & 3.131 & .013 & 2.269 & .743 & 8.001 & .175 \\
\hline $\begin{array}{l}\text { Sen Students With Ehc } \\
\text { Plan }\end{array}$ & 11.601 & .223 & 6.335 & .159 & 8.515 & .032 & 4.183 & .381 & 7.485 & .025 \\
\hline Attainment & 0.878 & .439 & 3.735 & .775 & 1.562 & .651 & 3.853 & .823 & 0.152 & .865 \\
\hline
\end{tabular}


Percentage of current grouping practices by Subject ${ }^{2}$

NFER Teacher Voice results/may 2018

\section{English}

\begin{tabular}{lccccc}
\hline \multicolumn{1}{c}{ Year group } & $\begin{array}{c}\text { Completely } \\
\text { Mixed }\end{array}$ & $\begin{array}{c}\text { Partially } \\
\text { Mixed }\end{array}$ & Sets & Streams & Other/ DK \\
\hline $\begin{array}{l}\text { Year } 7 \\
(\mathrm{n}=600)\end{array}$ & 26 & 17 & 34 & 11 & 12 \\
$\begin{array}{l}\text { Year } 8 \\
(\mathrm{n}=596)\end{array}$ & 18 & 18 & 40 & 11 & 12 \\
$\begin{array}{l}\text { Year } 9 \\
(\mathrm{n}=594)\end{array}$ & 16 & 16 & 46 & 10 & 12 \\
& & & & & \\
& & & & & \\
$\quad$ Year group & Mixed & $\begin{array}{c}\text { Martially } \\
\text { Mixed }\end{array}$ & Sets & Streams & Other/ DK \\
\hline $\begin{array}{l}\text { Year 7 } \\
(\mathrm{n}=595)\end{array}$ & 15 & 12 & 54 & 9 & 10 \\
$\begin{array}{l}\text { Year } 8 \\
(\mathrm{n}=595)\end{array}$ & 6 & 14 & 62 & 9 & 9 \\
$\begin{array}{l}\text { Year 9 } \\
(\mathrm{n}=593)\end{array}$ & 4 & 12 & 67 & 9 & 9
\end{tabular}

${ }^{2}$ As part of the questionnaire, respondents were requested to answer the following question: 'Please select the best description of current grouping practices in English in each year group in your school'. The respondents had to choose between nine options: 'Completely Mixed', 'Mixed+Top set', 'Mixed+bottom set', 'Mixed+Top+Bottom set', 'Sets', Streams', 'Other', 'Don't Know' and 'Not applicable'. The categories were collapsed using the main groups described along this paper. The percentages in these tables are weighted separately by FSM rates. Reported base sizes (N) are unweighted. 